\title{
EFFECTS OF CHEMICAL PROTECTIVE CLOTHING ON TASK PERFORMANCE USING WEARABLE INPUT DEVICES
}

\author{
Andrea S. Krausman \\ Thesis submitted to the faculty of the Virginia Polytechnic Institute \\ and State University \\ In partial fulfillment of the requirements for the degree of \\ MASTER OF SCIENCE \\ In \\ Industrial and Systems Engineering
}

\author{
Maury A. Nussbaum, PhD, Chair \\ Dr. Tonya L. Smith-Jackson, PhD \\ Dr. Thurmon E. Lockhart, PhD
}

August 2, 2004

Blacksburg, VA

Keywords: Interaction Devices, Safety, Human-Computer Interaction, Interface Design, Extreme Environments 


\title{
EFFECTS OF WEARING CHEMICAL PROTECTIVE CLOTHING ON TASK PERFORMANCE WHEN USING WEARABLE INPUT DEVICES
}

\author{
Andrea S. Krausman
}

\begin{abstract}
Wearable computers allow users the freedom to work in any environment including hazardous environments that may require protective clothing. Past research has shown that protective clothing interferes with manual materials handling tasks, medical tasks, and manual dexterity tasks. However, little information exists regarding how protective clothing affects task performance with wearable input devices. As a result, a study was conducted to address this issue and offer recommendations to enhance the compatibility of chemical protective clothing and wearable input devices.

Sixteen active-duty soldiers performed a text-entry task with a wearable mouse and touch pad, while bare handed, wearing 7-mil, 14-mil, and 25-mil chemical protective gloves, wearing a respirator alone, and wearing the respirator and each of three gloves. Upon completion of the experiment, participants rated task difficulty, confidence using the input device, and input device preference. Task completion times were 9\% slower with the 25 -mil glove than the 7-mil glove. Text entry was not perceived as difficult when bare handed, or wearing the 7-mil and 14-mil gloves, suggesting that thin chemical protective gloves (i.e. 7-mil and 14-mil) are more suitable than thicker gloves for use with wearable input devices. When using the touch pad, task completion times were $17 \%$ faster than when using the mouse. Subjective ratings of difficulty, confidence, and preference provide strong support for the use of a touch pad input device rather than a mouse.
\end{abstract}




\section{ACKNOWLEDGEMENTS}

First, I would like to express my gratitude to God for his "mercies that are new every morning", and for giving me the strength and ability to complete this work.

I am grateful to my committee members, Dr. Maury Nussbaum, Dr. Thurmon Lockhart, and Dr. Tonya Smith-Jackson who helped me throughout the completion of this research with their support and expertise. It was a privilege to have the opportunity to learn from you.

I would also like to express my gratitude to my co-workers at the Army Research Laboratory and the Director, Human Research and Engineering Directorate for their support and for making this opportunity possible.

I am indebted to my family and friends for their constant support, love, and prayers.

Finally, special thanks to my best friend and husband, Bob, who has supported me and encouraged me throughout this work. Thank you for your willingness to walk this path with me. Your love, support, and sacrifice have enabled me to reach this goal. 


\section{TABLE OF CONTENTS}

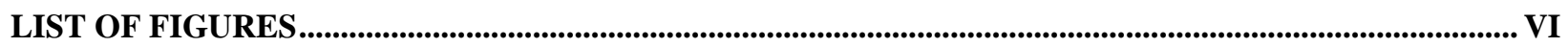

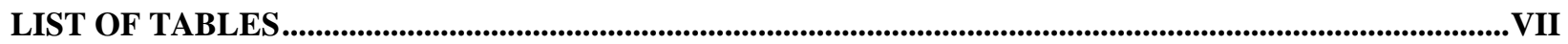

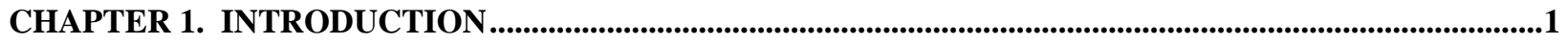

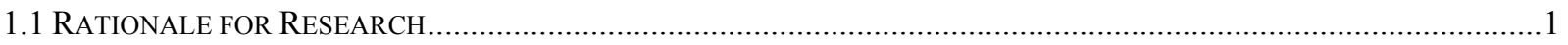

CHAPTER 2. REVIEW OF THE LITERATURE .................................................................................

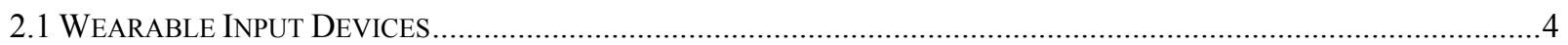

2.2 Chemical Protective Clothing AND TASK Performance ...................................................................

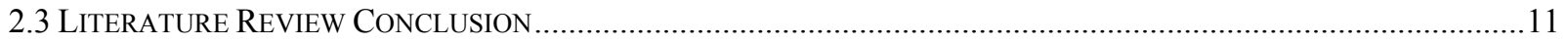

CHAPTER 3. RESEARCH OBJECTIVES .............................................................................................................13

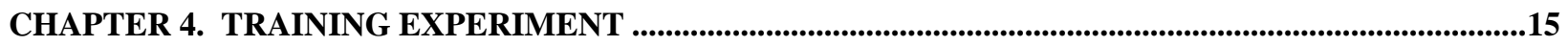

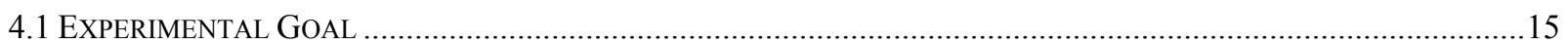

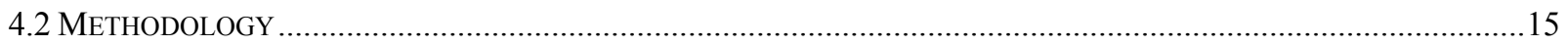

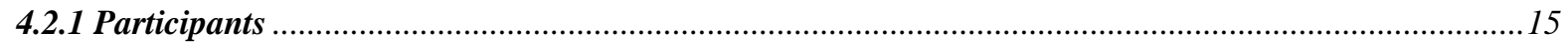

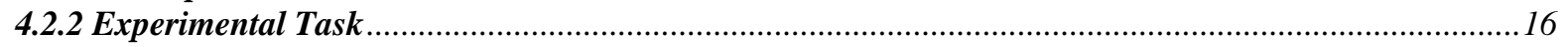

4.2.3 Experimental Equipment ..............................................................................................................

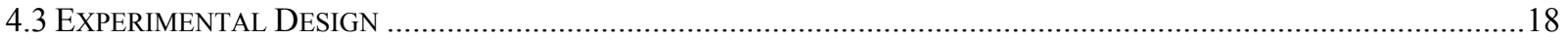

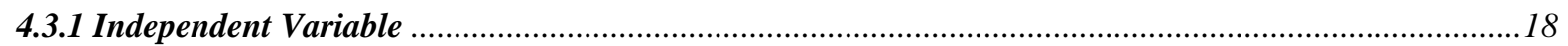

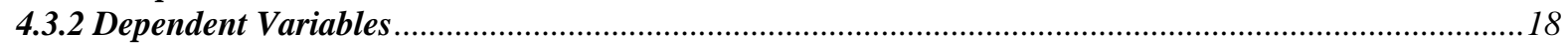

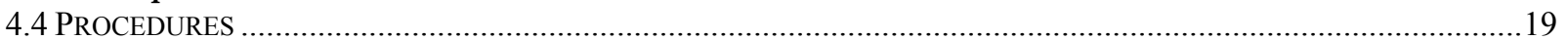

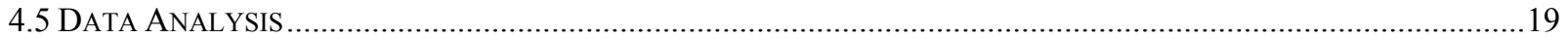

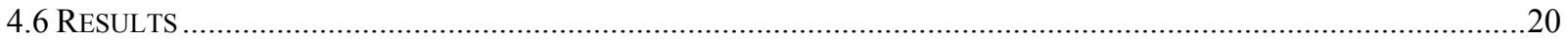

4.6.1 Mouse

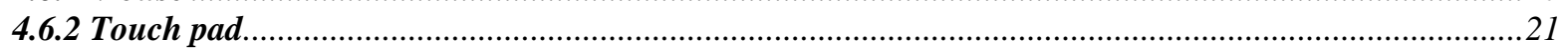

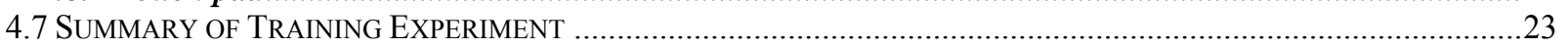

CHAPTER 5. DISPLAY-CONTROL GAIN EXPERIMENT..............................................................................24

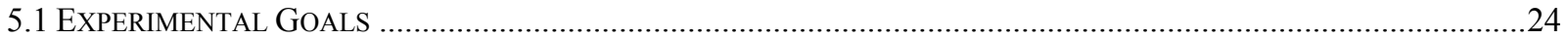

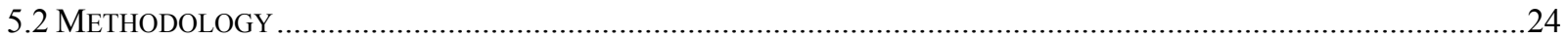

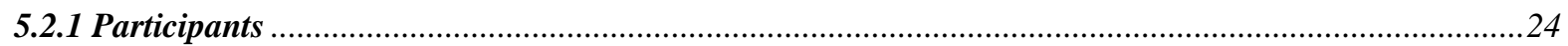

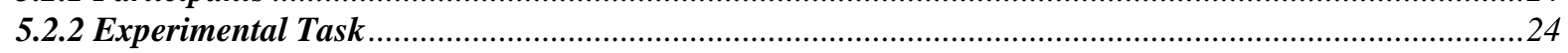

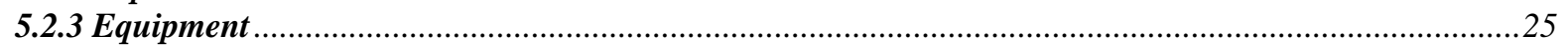

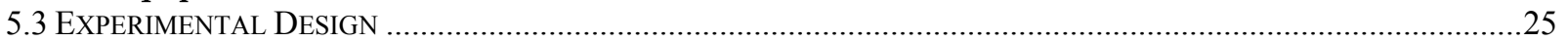

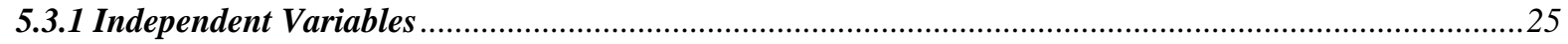

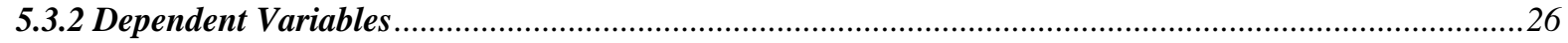

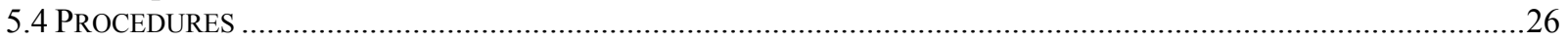

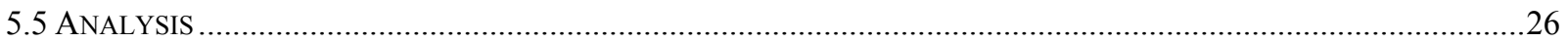

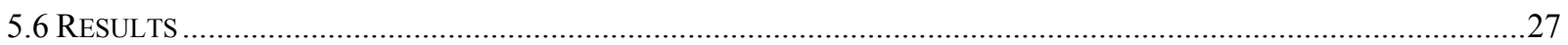

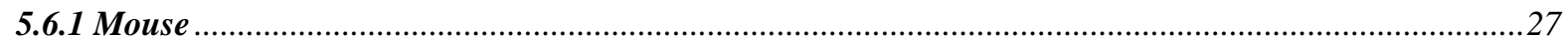

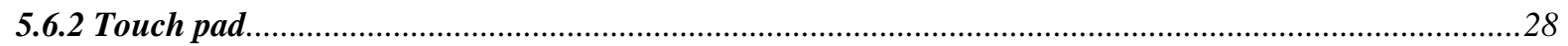

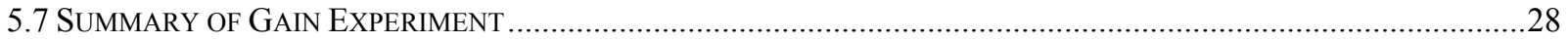

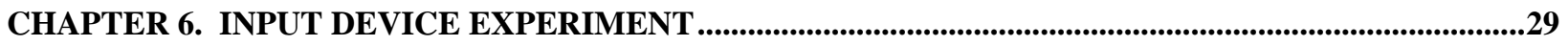

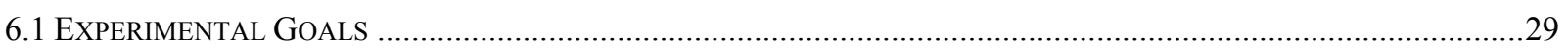

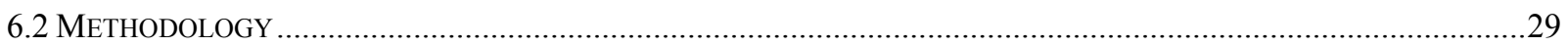

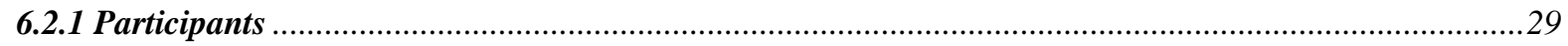

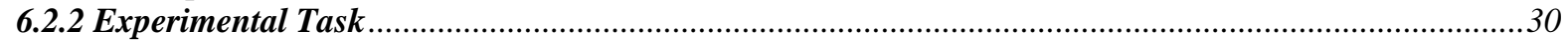




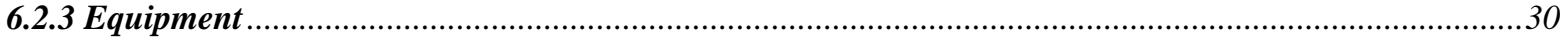

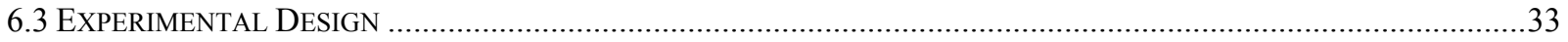

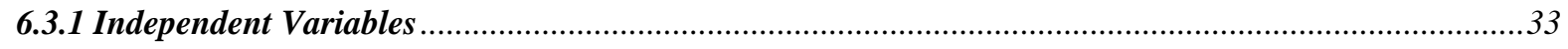

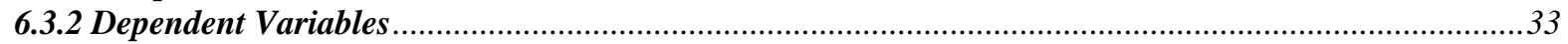

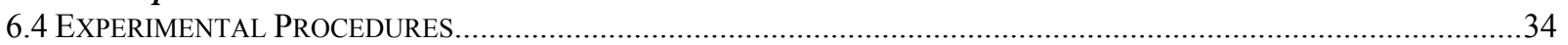

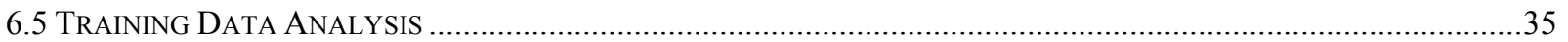

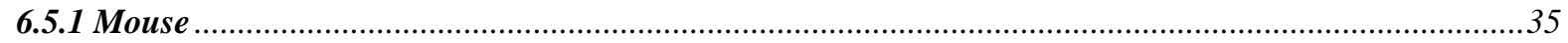

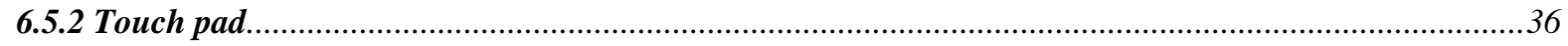

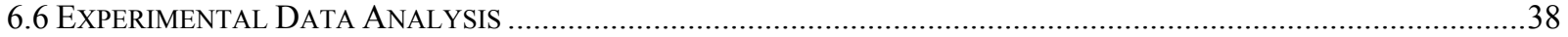

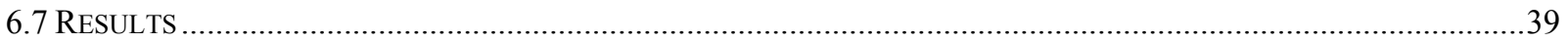

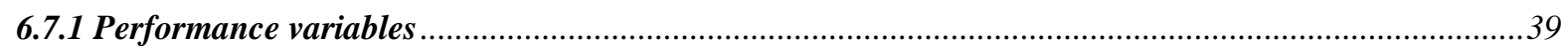

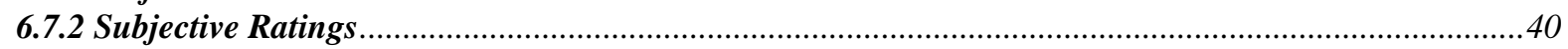

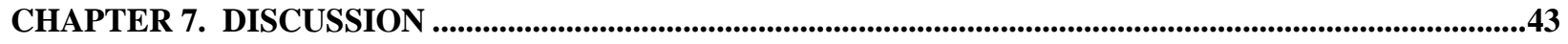

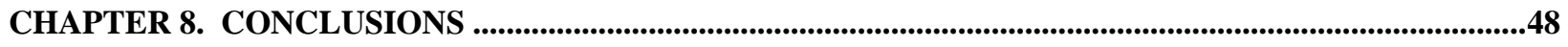

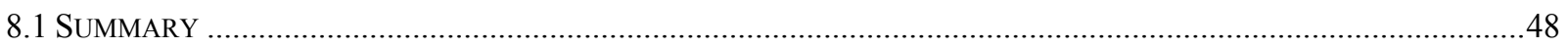

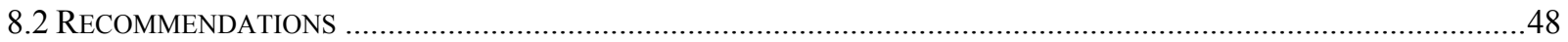

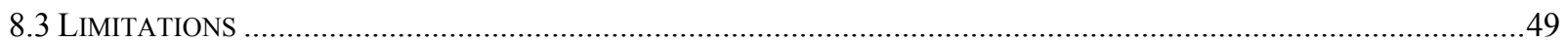

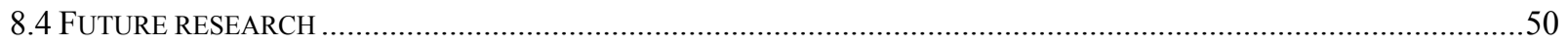

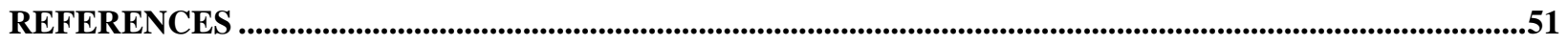

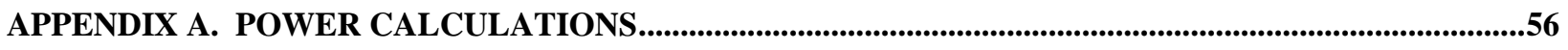

APPENDIX B. VOLUNTEER AGREEMENT AFFADAVIT ...................................................................59

APPENDIX C. CHEMICAL PROTECTIVE JACKET SIZING CHART ......................................................63

APPENDIX D. RESPIRATOR FIT CRITERIA .......................................................................................65

APPENDIX E. INPUT DEVICE QUESTIONNAIRE ................................................................................67

APPENDIX F. HEALTH AND DEMOGRAPHICS QUESTIONNAIRE .......................................................71

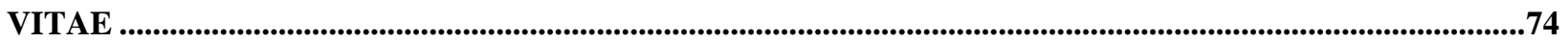




\section{LIST OF FIGURES}

Figure 1. Example Alphanumeric Text Entry Task and On-screen Keyboard.............................................16

Figure 2. Mouse (A) and Touch Pad (B) Input Devices................................................................................17

Figure 3. Liteye400 ${ }^{\mathrm{TM}}$ Helmet-Mounted Display ..............................................................................................18

Figure 4. Task completion times in training sessions using the mouse .................................................................21

Figure 5. Number of errors in training sessions using the mouse ..........................................................................21

Figure 6. Task completion times in training sessions using the touch pad ....................................................22

Figure 7. Number of errors in training sessions using the touch pad ............................................................22

Figure 8. Chemical protective gloves and liner .........................................................................................31

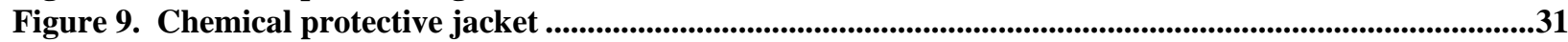

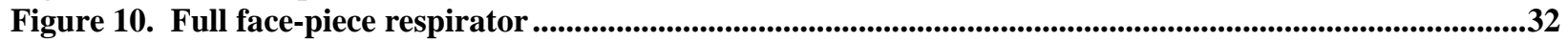

Figure 11. Task completion times for training sessions using the mouse................................................................36

Figure 12. Number of errors in training session using the mouse ...................................................................36

Figure 13. Task completion times for training sessions using the touch pad....................................................37

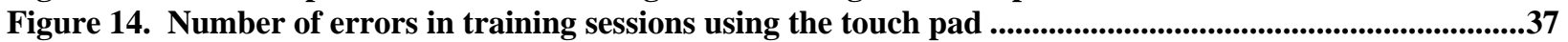

Figure 15. Task completion times for the four glove conditions...........................................................................39

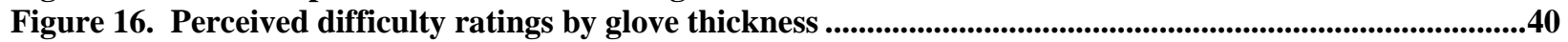

Figure 17. Interaction between device and mask ............................................................................41 


\section{LIST OF TABLES}

Table 1. United States Army Mission-Oriented Protective Posture (MOPP) Levels................................................8

Table 2. Gain experiment balanced Latin square design .................................................................................25

Table 3. Gain settings and definitions ..............................................................................................................................25

Table 4. Decision criteria for optimum gain.................................................................................................................27

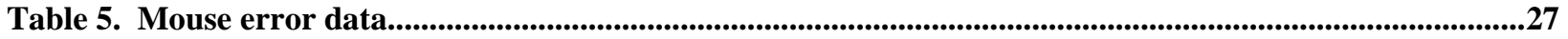

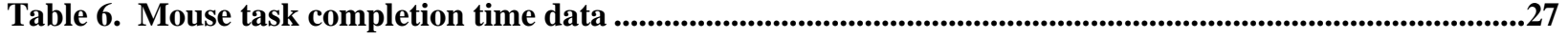

Table 7. Touch pad error data......................................................................................................................................28

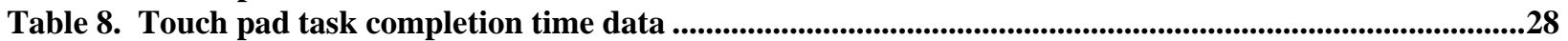

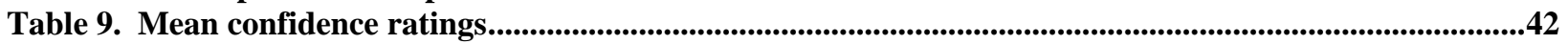




\section{CHAPTER 1. INTRODUCTION}

\subsection{Rationale for Research}

Wearable computers are portable, self-contained devices that can be mounted on a belt or carried in a backpack. One of the main goals of wearable computers is to allow users to access information wherever they may be in the physical environment (Barfield and Baird, 1998). An advantage of wearable computers is that they can be used in a variety of settings outside the benign environment of an office or laboratory. For instance, wearable computers have been used as a navigation tool for the disabled and by maintenance technicians for vehicle troubleshooting and repair (Bass, Mann, Siewiorek, and Thompson, 1997). Other application areas include medicine, manufacturing, and architecture (Barfield and Baird, 1998).

One of the components of desktop and wearable computers is an input device that allows the user to select, move, and manipulate objects presented on a visual display. Desktop input devices like mouse devices, trackballs, and touch pads are not suitable as input devices for wearable computers, because they require a large, flat surface to operate, which may not be available when using a wearable computer. In addition, desktop input devices are designed for office environments, and are not sufficiently rugged for use in environments that are hostile to the use of computers (i.e. swampy terrain, mud, dust).

There are unique challenges in designing input devices for wearable computers. Namely, wearable input devices must be able to be used with one hand, when outside of the user's fieldof-view, at any orientation, and in any environment (Billinghurst, Bowskill, Dyer, and Morphett, 1998). The majority of research into the design of wearable input devices has addressed how the device should be oriented on the body (Thomas, Grimmer, Makovec, Zucco, and Gunther, 1999), 
the use of hands-free technologies (Calhoun and McMillian, 1998), and the usability of wearable input devices for text entry tasks (Thomas, Tyerman, and Grimmer, 1997). However, information regarding the usability of wearable input devices in hazardous environments is lacking.

One sector in which wearable computers are of particular current interest is the U.S. military. Combat soldiers, like civilian first responders, will use wearable computers to acquire and transmit data in hazardous environments, which may include a hazardous materials spill or the release of a chemical or biological agent (USGAO, 1999). Increasing threats of nuclear, chemical, and biological (NBC) weapons make it critical to understand how task performance may suffer in a contaminated environment. In the event of contamination, personnel don chemical protective clothing, consisting of a respirator with hood, a suit (jacket and pants or coveralls), boots, and butyl rubber gloves. Although these components offer protection, they can interfere with task performance. For example, wearing protective gloves can reduce manual dexterity, increase performance time, and impair precision of movement (Oborne, 1988).

Initial tests of wearable systems for the combat soldier have addressed the weight and power of the computer, yet none have examined the compatibility of chemical protective clothing and wearable input devices. Rather, equipment developers have assumed that input devices designed and tested in non-hazardous environments are also suitable for use in hazardous environments. This assumption has not been tested. If task performance with a wearable input device is degraded when wearing chemical protective clothing, consequences may be severe or even deadly because soldiers and surety workers will be unable to receive and transmit information critical to their survival. 
Determining how chemical protective clothing affects task performance with wearable input devices is thus important in the design of wearable input devices and in the selection of compatible chemical protective clothing. For example, a 25-mil chemical protective glove may degrade task performance considerably more than a 14-mil or 7-mil glove. Such information will assist wearable computer designers as well as individuals responsible for the development of protective clothing and equipment. The overall purpose of this research, therefore, was to provide new information regarding the effects of chemical protective clothing on performance when using wearable input devices. 


\section{CHAPTER 2. REVIEW OF THE LITERATURE}

\subsection{Wearable Input Devices}

A wearable computer is comprised of several components; a computer unit that is typically a belt-mounted or backpack PC, a head-mounted or wrist-mounted display, wireless communications hardware, and an input device, such as a joystick. The defining characteristic that separates wearable computers from more traditional forms of portable devices such as hand held computers, laptop computers, and personal digital assistants (PDAs), is that a wearable computer runs continuously, and is "always ready" to interact with the user (Billinghurst and Starner, 1999). Wearable systems have wide application, including process monitoring, product inventory, and field data collection. These tasks are usually performed in two steps when using a desktop computer. Data is first collected using a pen and paper, and then it is entered into a computer, which can be time-consuming and error prone. When using a wearable computer, tasks can be performed in a single step thereby saving time and reducing error rates (Thomas, Tyerman, and Grimmer, 1997).

A key component of any computer system is the input device, which allows the user to select and manipulate objects, enter text, and navigate through menus. All input devices can be categorized as indirect control or direct control. An indirect input control device requires a secondary device (i.e. mouse button, keyboard key, etc.) to move the cursor and select objects. Examples of indirect control devices include a mouse, joystick, trackball and cursor keys (Baber, 1997). Direct input control devices do not utilize a secondary device for pointing and object selection; rather the user simply touches an object on the display to select it. Indirect control input devices can be used with a helmet mounted display (HMD) or a wrist-mounted display 
(WMD), however direct input control devices can only be used with WMDs. Since an HMD will be used in the proposed research, only indirect control devices will be included (Spencer, 2000).

Several studies have compared different input devices for desktop computing (Milner, 1988; Douglas and Mithal, 1997; Card, English, and Burr, 1978; and Epps, 1986). Results of these studies have been used to establish guidelines for selecting input devices for use with desktop computers. These guidelines, however, have been developed specifically for the benign office-computing environment, and cannot be adequately applied to wearable computers, that is, many desktop input devices are also too large and cumbersome to use in a field setting, especially when additional equipment (i.e. a measurement device or monitor) may be needed to perform a task. In addition, current desktop input devices are not practical for users standing in an outdoor environment, because they require a flat surface to operate correctly.

Advances in wearable computer technology and the growing popularity of wearable systems have created an interest in the design and evaluation of wearable input devices (Barfield et al., 1998). Despite this, only a few studies have evaluated the performance of input devices for wearable systems. Thomas, Tyerman, and Grimmer (1997), determined the usability of three input devices for text entry tasks using a wearable computer. Participants used a forearmmounted keyboard, a Kordic keypad, and a belt-mounted mouse to create and save short text messages. The forearm keyboard provided the most accurate and efficient text entry. Placement of an input device on the body and the posture of the user have also been shown to affect task performance. In a study by Thomas et al. (1999), participants performed a target selection task with a touch pad placed on the user's torso, upper arm, or thigh, while standing, sitting, kneeling, and in a prone position. The best position for the mouse for a sitting or kneeling posture, and the 
forearm was the best position when the user was in the prone position. Task performance was significantly degraded while in the prone position. Barfield et al. (1998) suggested that bodymounted, handheld, or wrist-mounted keyboards or track pads are best for tasks that do not require hands-free capability.

As noted earlier, wearable input devices are usually mounted on the body to enable onehanded operation. For tasks that require hands-free operation of the computer, an alternative input device such as speech recognition is a potential solution. Speech technology is considered a suitable alternative for some wearable computer applications because it does not require the use of the hands or fingers to interact with the system, so it is practical for occupations or situations in which the user's hands are occupied with equipment or a weapon. Although speech recognition is promising, several limitations must first be overcome before speech input can be utilized as an input mechanism for wearable computer users. Namely, environmental noise can mask or interfere with speech making voice recognition difficult (Durlach \& Mavor, 1995). There may also be situations (i.e. combat) that require the user to remain quiet, which makes it difficult to utter spoken commands. In addition, tasks such as drawing or target acquisition are not conducive to speech input control (Cleveland \& McNinch, 1999). Other technologies such as eye-based control, gesture-based control, electromyography (EMG)-based control, and electroencephalograph (EEG)-based control have been developed to allow hands-free operation of a wearable computer (Calhoun et al., 1998). Each of these technologies has potential for a range of tasks and environments, yet these alternative interaction devices still need considerable development before they can be considered as a viable means of interacting with a wearable computer. This research therefore focused on current input device technologies. 
An important issue that has not been addressed in the literature is the effect of protective clothing on performance using wearable input devices, a surprising limitation considering that wearable computers are intended as mobile systems that can be used in any environment. Normal operation of wearable computers is often conducted when physical performance is restricted by some form of protective clothing (Baber, 1997). For example, a soldier, first responder, or hazardous materials worker using a wearable computer may suddenly face a hazard that would require them to don protective clothing, which has been shown to hinder task performance. Wearable computers provide a technological edge, but in order to be effective, the components must be designed so that they are compatible with chemical protective clothing.

\subsection{Chemical Protective Clothing and Task Performance}

Chemical protective clothing (CPC) is worn in a variety of industrial and military settings to protect workers from exposure to potentially hazardous solvents, materials, and chemical agents. The components of CPC are: (a) a gas mask with a respirator; (b) a protective hood that covers the head and shoulders; (c) a suit (trousers and overcoat, or coveralls); (d) rubber protective gloves; and (e) rubber over boots. The CPC ensemble can be worn in various configurations, depending on the required level of protection. Both the military and commercial sectors provide guidelines to obtain the appropriate level of protection. These guidelines, although different, illustrate the various combinations of chemical protection that are utilized. The U.S. Army uses the term Mission Oriented Protective Posture (MOPP), when referring to the various levels of chemical protection (Table 1). Maximum protection is achieved when all components of the CPC ensemble (gas mask, hood, suit, gloves, and mask) are worn (Krueger and Banderet, 1997). 
Table 1. United States Army Mission-Oriented Protective Posture (MOPP) Levels

MISSION ORIENTED PROTECTIVE POSTURE (MOPP) CONFIGURATIONS

MOPP Level 0. No general warning and the threat of NBC Warfare does not exist. Mask and hood are carried. Over-garment, over-boots, gloves are readily available.

MOPP Level I. General warning is given and the threat of NBC Warfare exists. Mask and hood are carried. Over-garment is worn open or closed, based on temperature. Over-boots and gloves are carried.

MOPP Level II. Tactical situations that require units to cross terrain where the previous use of chemical agents is known. Mask and hood are carried. Over-garment is worn open or closed, based on temperature. Over-boots are worn and gloves are carried.

MOPP Level III. Units are on the move and a chemical attack is possible. Mask and hood are worn, hood open or closed, based on temperature. Over-boots are worn and gloves carried.

MOPP Level IV. Unit will be operating within an area of contamination, or if there is an imminent threat of attack. Mask and hood are worn and closed. Over-garment is worn and closed. Over-boots and gloves are worn.

(Adapted from U.S. Army Field Manual 3-4, 1996)

One concern addressed in the literature is the degree to which CPC degrades task performance. CPC has been shown to impose a physiological and psychological burden that can degrade performance (Arad, Berkenstadt, Zelhinger, Laor, Shemer, and Atsmon, 1993). For example, the gas mask may increase breathing resistance, restrict field-of-view, and interfere with speech intelligibility (Muza, 1986). The protective suit often causes heat stress and subjective discomfort during continuous operation in hot and humid conditions (Arad et al., 1993; Caldwell, Caldwell, \& Salter, 1997; Fine, 1987; White, Hodous, \& Vercruyssen, 1991). Chemical protective gloves can hinder manual dexterity and control operation, depending on the thickness of the glove (Arad et al., 1993; Bensel, 1993; King \& Frelin, 1984).

While the majority of research into the effects of $\mathrm{CPC}$ on task performance has focused on gross motor tasks such as mounting and dismounting a vehicle, and carrying a patient on a 
litter, only a few studies have examined the effects of CPC on manual dexterity. These studies have focused on the effects of $\mathrm{CPC}$ on task performance in three primary areas: medicine, hazardous materials handling, and the military. Arad, Berkenstadt, Zelingher, Laor, Shemer, \& Atsmon (1993) investigated the effect of prolonged physical protection on the performance of medical tasks. The tasks performed in this study required fine motor skills, manual dexterity, and hand-eye coordination. Emergency medical technicians (EMTs) performed the tasks over an 8-hour period, while wearing different configurations of MOPP or their regular uniform. Participants performed all of the tasks successfully; however, there was a 30\% increase in task completion time when wearing the MOPP gear. Similar results were reported in a study that investigated the ability of medical staff to perform life saving procedures while wearing a chemical protective suit (Coates, Jundi, \& James, 2000). In this study, participants had difficulty performing tasks requiring fine movements or delicate control, and found the butyl rubber gloves to be bulky and awkward.

Other research has focused on the effect of wearing chemical protective gloves on performance of hazardous materials handling tasks (Plummer, Stobbe, Ronk, Myers, Kim, and Jaraiedi, 1985). Participants used screwdrivers and wrenches to perform a nut-bolt-washer assembly-disassembly task while barehanded, wearing a single chemical protective glove, or while wearing a combination of an inner and outer glove. Response time and errors were measured, where dropping a tool or other item constituted an error. Gloves increased the average task completion time by 15 to $30 \%$, and error rates increased with the double-glove combination.

Task performance while wearing $\mathrm{CPC}$ is also a major concern for soldiers, who must be able to perform their mission in a chemically contaminated environment. Bensel (1980) found 
that a soldier's manual dexterity is compromised when wearing chemical protective gloves. In this study, participants performed a battery of six manual tasks while bare handed and wearing neoprene and butyl rubber gloves. On the finger dexterity task, task completion time was $24 \%$ longer when wearing the butyl gloves, and 27\% longer when wearing the neoprene gloves, relative to bare hand performance. Other researchers (Johnson and Sleeper, 1986; Robinette et al., 1986) also found that wearing chemical protective gloves reduces manual dexterity when compared to bare hand performance.

Glove thickness is also a factor that limits manual dexterity. Bensel (1993) investigated the effect of three thicknesses $(0.18 \mathrm{~mm}, 0.36 \mathrm{~mm}$, and $0.64 \mathrm{~mm})$ of chemical protective butyl rubber gloves on five manual dexterity tasks. Mean performance times on the finger dexterity task were $20 \%$ slower with the thickest glove $(0.64 \mathrm{~mm})$, compared to bare hand performance, and approximately $10 \%$ slower compared to the thinner gloves $(0.18 \mathrm{~mm}$ and $0.36 \mathrm{~mm})$.

Although the majority of the research into task performance while wearing chemical protective clothing has focused on performance while wearing chemical protective gloves, some studies have examined the combined effect of gas mask, hood, and gloves on manual dexterity. Results of these studies have been inconsistent. Johnson et al. (1986) investigated the effects of butyl rubber gloves and a gas mask with hood on manual dexterity. A pegboard tasks and a finger dexterity task were performed while (1) bareheaded and barehanded, (2) barehanded and wearing a gas mask with hood, (3) bareheaded and wearing gloves, and (4) wearing the gas mask with hood and gloves. Gloves produced a significant decrement in manual dexterity, but wearing the mask and hood had no effect on dexterity. The authors concluded that it takes longer to become skilled at manual dexterity tasks when wearing gloves than when barehanded. Some participants took up to three times as long to perform the Purdue Pegboard Task when wearing 
gloves compared to the barehanded condition. Work by Bensel, Teixeira, and Kaplan (1987) indicated that wearing the gas mask, hood, and gloves resulted in significantly longer completion times on a finger dexterity test, than when wearing the regular duty uniform or just the protective suit. In this study, a finger dexterity task, pegboard task, and a target-tracking task were performed while wearing their normal duty uniform, the chemical protective suit, and the complete chemical ensemble (including gas mask and hood). In the target-tracking task, time on target decreased slightly when wearing either the gas mask or the gloves as compared to wearing the protective suit alone. The authors suggested that the butyl rubber gloves had the largest effect on dexterity; although the gas mask also had an effect, it was not as pronounced.

Studies cited in this literature review indicate that CPC does affect manual dexterity. Several of these studies measured performance on standardized tests of manual dexterity, such as placing pegs in a pegboard, or using a tool to manipulate nuts and bolts. As yet, none has directly assessed the effects of CPC on specific job-related tasks requiring manual dexterity, such as data entry using a computer. In order for CPC to be effective, it must be compatible with computers and other equipment used to perform job-related tasks, which may include a wearable computer.

\subsection{Literature Review Conclusion}

As discussed in the previous sections, wearable computers allow users access to information in any environment, including those that require the user to don protective clothing. Users manipulate an input device to enter data, manipulate objects, and navigate through menus. Users may be required to perform these tasks in a contaminated environment while wearing CPC, which has been shown to limit manual dexterity, therefore it is essential that wearable input devices are designed to be compatible with protective clothing. The main objective of this 
research was, therefore, to determine how task performance with wearable input devices is affected when wearing CPC. 


\section{CHAPTER 3. RESEARCH OBJECTIVES}

The proposed study identified performance decrements that occur when wearing chemical protective clothing and incorporated these results with existing evidence to develop recommendations for the design and use of wearable input devices with chemical protective clothing. The research focused on performance speed and number of errors as participants performed alphanumeric text entry using wearable input devices.

Several specific questions were addressed in the proposed study. First, what impact does wearing chemical protective gloves have on manipulation of wearable computer input devices? Input devices for future wearable computers will most likely be small and mounted on the body. Bulky chemical protective clothing may make it difficult for users to manipulate the controls with their hand. As a result, it is important to determine if there are any changes in speed and accuracy while wearing chemical protective gloves. Second, what impact does wearing a chemical protective mask have on manipulation of wearable computer input devices? Existing literature suggests that wearing a chemical protective mask can restrict the field-of-view and interfere with visual-motor coordination tasks, so it is important to determine how wearing a chemical protective mask effects input device manipulation. Third, what impact does wearing both a chemical protective gas mask and gloves have on manipulation of wearable computer input devices? A wearable computer may be used in an environment that requires the user to wear both the chemical protective mask and gloves. Existing literature suggests that the combination of chemical mask and gloves does affect manual dexterity. As a result, it is important to determine the effect that the combination of chemical mask and gloves have on manipulation of input devices. Fourth, how much of the degradation in performance can be attributed to each of the components of chemical protective clothing? As noted, there is prior 
evidence that wearing chemical protective mask and gloves affects manual dexterity, yet there is little information regarding how much each component of chemical protective clothing degrades performance. Often, the type of threat and threat level determines what components of chemical protective clothing are worn. Performance may differ depending on what components of CPC are worn. Results from this study will be used to quantify the performance degradation for the chemical protective mask and gloves.

To accomplish the research objective, three experiments were completed. The first experiment was to determine the number of training trials necessary for participants to become well practiced with the mouse and touch pad. The second experiment was performed to determine if changing the display-control (D-C) gain would affect pointing performance for the mouse and touch pad. Results of the first and second experiments were incorporated into the third, or formal experiment, which was conducted to determine how performance on a text entry task is affected when wearing chemical protective clothing. 


\section{CHAPTER 4. TRAINING EXPERIMENT}

\subsection{Experimental Goal}

The goal of this preliminary experiment was to determine the number of training trials necessary for participants to become well practiced with the mouse and touch pad input devices. Adequate training helps reduce the likelihood of practice effects and allows participants a chance to become familiar with how the input devices operate. Card, English, and Burr (1978) examined performance on a pointing task with four desktop input devices and concluded that participants became well-practiced when performance between consecutive trials ceased to improve. Similarly, for this experiment, participants performed a text entry task until there was no longer any significant improvement in performance (i.e. task completion time and number of errors) between consecutive trials. Results were used to establish a training criterion for the formal experiment.

\subsection{Methodology}

\subsubsection{Participants}

Six participants, three males and three females, were recruited from the employee population at the U.S. Army Research Laboratory. All participants were between the age of 23 and 48 years old, and met the visual acuity requirements of 20/30 corrected or uncorrected. Visual acuity was verified with a Titmus ${ }^{\circledR}$ vision tester. 


\subsubsection{Experimental Task}

Participants performed text entry tasks in all three experiments. Text entry was chosen because it is a task that computer users frequently perform and has been used in similar experiments (Thomas et al., 1997; Middlebrooks and Spencer, 2000). The text entry tasks were developed using words and numbers. Words were taken from the Teacher's Word Book of 30,000 words, which contains the most frequently used words in the English language (Thorndike and Lorge, 1944), and numbers were selected from a list of random numbers. Each task consisted of entering 60 characters: 8 numbers, 41 letters, and 11 spaces. Tasks were scored using a Visual Basic program, and generated by a laptop computer, along with the On-screen keyboard in Windows $98 \circledR$ (Figure 1). Participants performed eight text entry tasks during the training experiment. The eight tasks were presented in a random order.

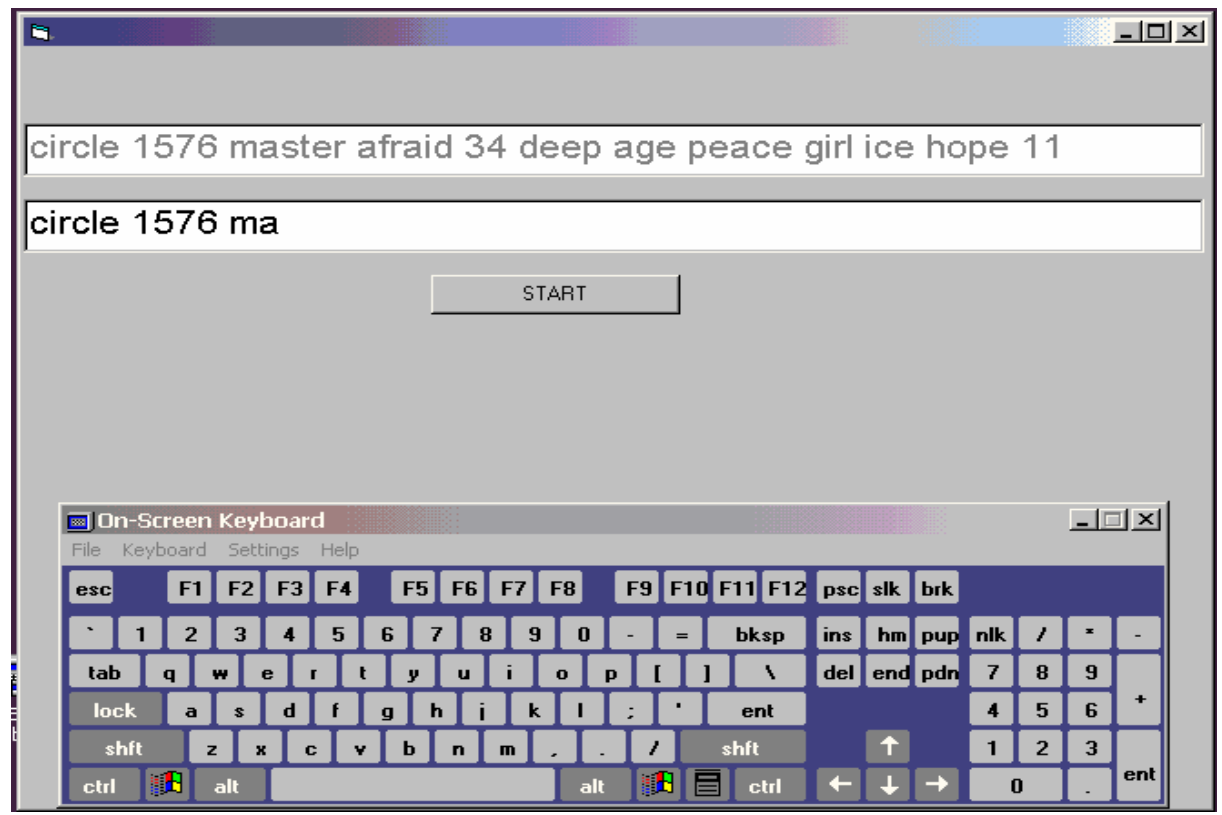

Figure 1. Example Alphanumeric Text Entry Task and On-screen Keyboard 


\subsubsection{Experimental Equipment}

Two commercially available input devices were used to perform the text entry task: 1) A mouse (Figure 2A, Interlink Electronics), approximately $7.0 \mathrm{~cm}$ long x $3.8 \mathrm{~cm}$ wide x $1.5 \mathrm{~cm}$ deep; and 2) The Easy Cat ${ }^{\mathrm{TM}}$ Touch pad (Figure 2B, Cirque ${ }^{\circledR}$ Corporation), approximately 7.0 $\mathrm{cm}$. long x $8.6 \mathrm{~cm}$. wide x $1.3 \mathrm{~cm}$. deep, and $100 \mathrm{~g}$ in mass. These devices were selected because they are compatible with wearable computers and are rugged enough for wearable computing applications.

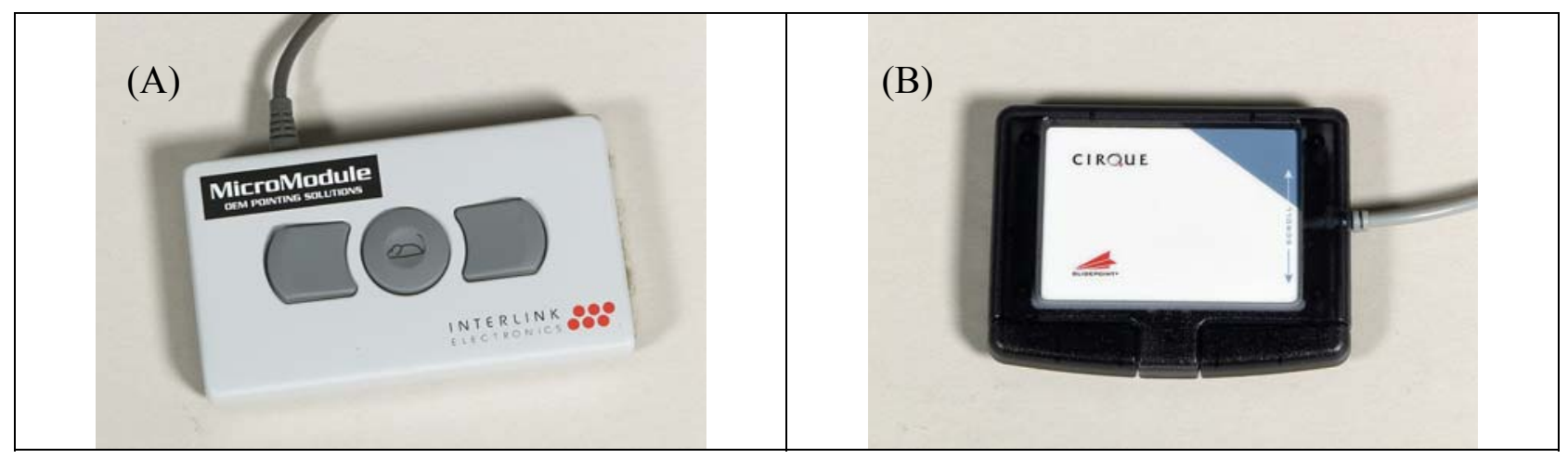

Figure 2. Mouse (A) and Touch Pad (B) Input Devices

A Liteye $400^{\mathrm{TM}}$ ruggedized helmet-mounted display (HMD, Figure 3), and the input devices were attached to the laptop through the USB ports. The On Screen Keyboard and text entry task were generated by the laptop and displayed on the HMD, which weighs approximately 1.5 ounces, and provides features similar to other helmet-mounted displays used in the military and commercial sectors, including full color and gray scale capability, a $38^{\circ}$ Field of View (FOV), and $800 \times 600$ resolution. 


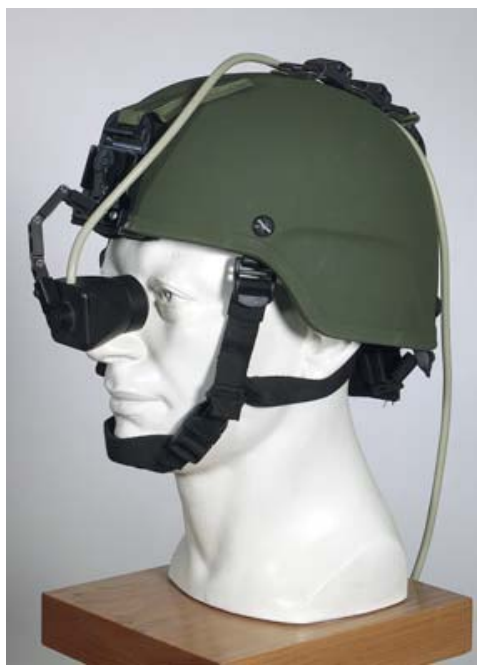

Figure 3. Liteye400 ${ }^{\mathrm{TM}}$ Helmet-Mounted Display

\subsection{Experimental Design}

\subsubsection{Independent Variable}

A within-subject design was used, with input device as the independent variable.

Presentation order of input devices was counterbalanced so that half of the participants used the mouse first, and half used the touch pad first.

\subsubsection{Dependent Variables}

Task completion time and number of errors were the dependent variables, and were recorded by a program created in Visual Basic. Participants pressed the start button to begin entering text and the stop button when they finished entering the last character. Task completion time was defined as the time between pressing the start and stop buttons. Number of errors was determined by comparing the characters the participant entered with the expected characters. An 
error was registered when a character other than the expected character was entered, or if fewer than 60 characters were entered.

\subsection{Procedures}

Participants performed eight training sessions with each input device. For consistency, the input devices were attached to the forearm using a Velcro sleeve. Participants remained seated in order to avoid performance changes that may result from other postures being adopted. In the first session, participants were introduced to the input devices and how they operate, while the following seven sessions were treated as actual training sessions. Participants were instructed to perform the text entry tasks as accurately as possible, without sacrificing speed, and were told not to correct errors. Accuracy was emphasized because, as mentioned previously, wearable computer users will receive and transmit information that is critical to their survival and this information must be accurate. After completing this experiment, participants performed the gain experiment.

\subsection{Data Analysis}

Data from the first training session was considered practice and was discarded. Task completion time data for the remaining seven training sessions was converted to seconds. To ensure that the number of characters entered was consistent across all sessions (i.e. at least 60 characters were entered by each participant for all training sessions), trials with less than 60 characters were assessed a penalty using the following formula:

$$
\begin{gathered}
\text { Corrected } \\
\text { Time }
\end{gathered}=\left[\frac{\begin{array}{c}
\text { Original task } \\
\text { completion time }
\end{array}}{\begin{array}{c}
\text { Number of characters } \\
\text { entered }
\end{array}} \times(60-\text { number of characters entered })\right]+\begin{gathered}
\text { Original task } \\
\text { completion time }
\end{gathered}
$$


Performance on consecutive training sessions was recorded and analyzed separately for the mouse and touch pad. Participants were considered well trained when there was no longer any significant improvement in task completion time or number of errors.

Task completion times and errors were examined for each device to identify errors or outliers and to assess the shape of the distributions. No recording errors were apparent, and neither the task completion times nor number of errors followed a normal distribution. A reciprocal transformation of the task completion time data yielded a distribution close to normal, and these values were analyzed using a repeated measures ANOVA. No transformation for the error data were found that yielded a normal distribution, so a Friedman nonparametric ANOVA was performed. Post-hoc comparisons were made using Tukey's HSD test. All statistical tests were considered significant when $p \leq 0.05$.

\subsection{Results}

\subsubsection{Mouse}

A significant main effect of session was found on the task completion times, $F(6,30)=$ 4.73, $p=.0017$. Across participants, task completion time was fairly consistent in the first four sessions, and decreased approximately 50 second afterwards (Figure 4). Of the pairwise comparisons, only the difference between sessions 4 and 5 were significant, $F(1,5)=18.11, p=$ 0.0080. Session did not have a significant effect on errors, $F(6,30)=1.04, p=0.4215$, and no trend was apparent (Figure 5). 


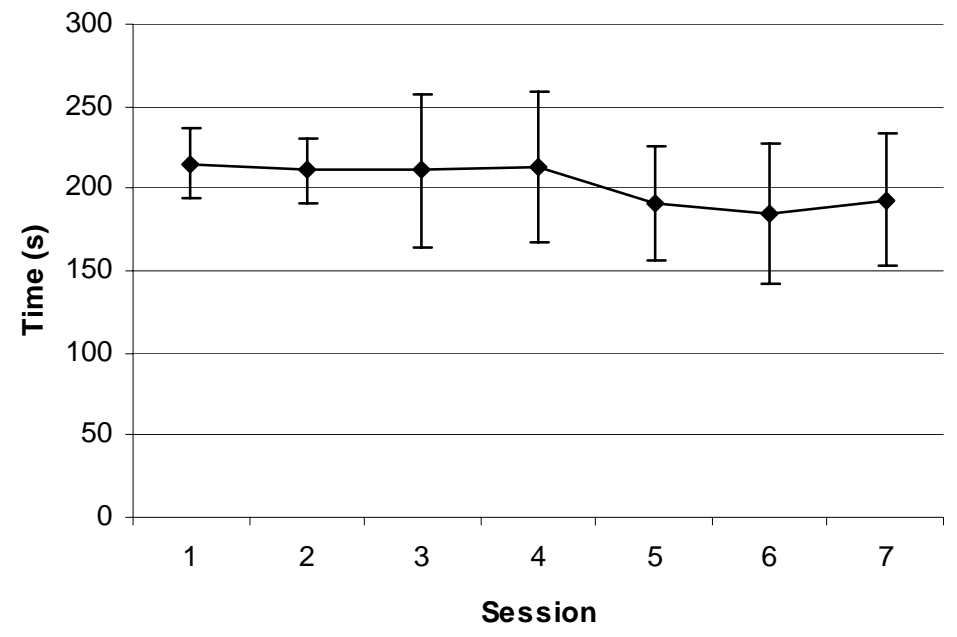

Figure 4. Task completion times in training sessions using the mouse

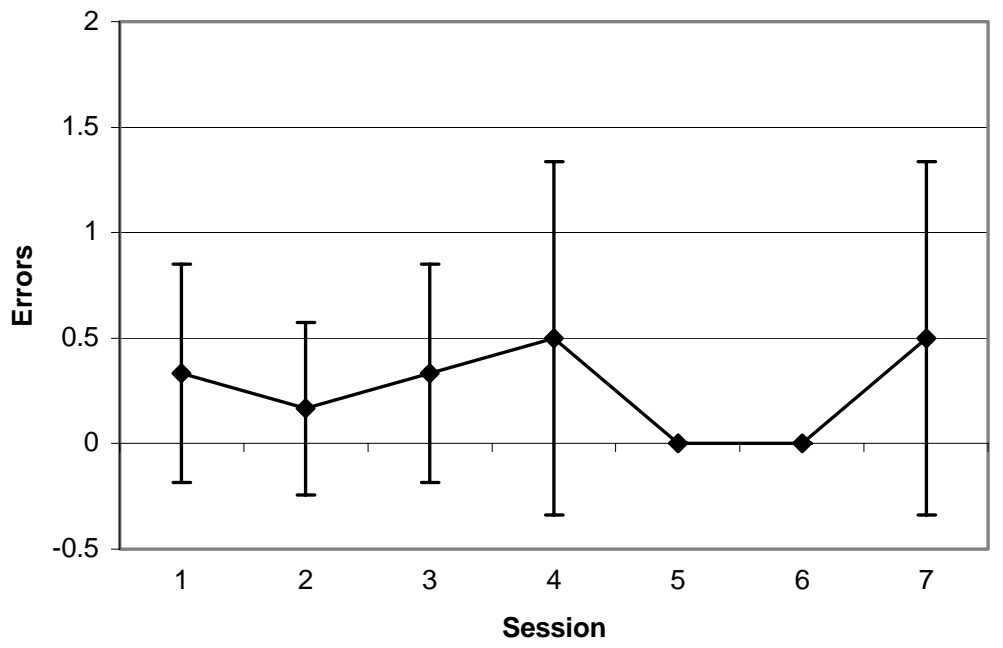

Figure 5. Number of errors in training sessions using the mouse

\subsubsection{Touch pad}

A significant main effect of session was found on the task completion time data, $F(6,30)$ $=6.45, p=0.0002$. Across participants, task completion time was longer for the first two training sessions than the last five. Of the pairwise comparisons, session 2 was significantly longer than that of session 3. Task completion time for the remaining training sessions was 
consistent. Session did not have a significant effect on errors, $F(6,30)=0.41, p=0.8680$, and no trend was apparent (Figures 6 and 7).

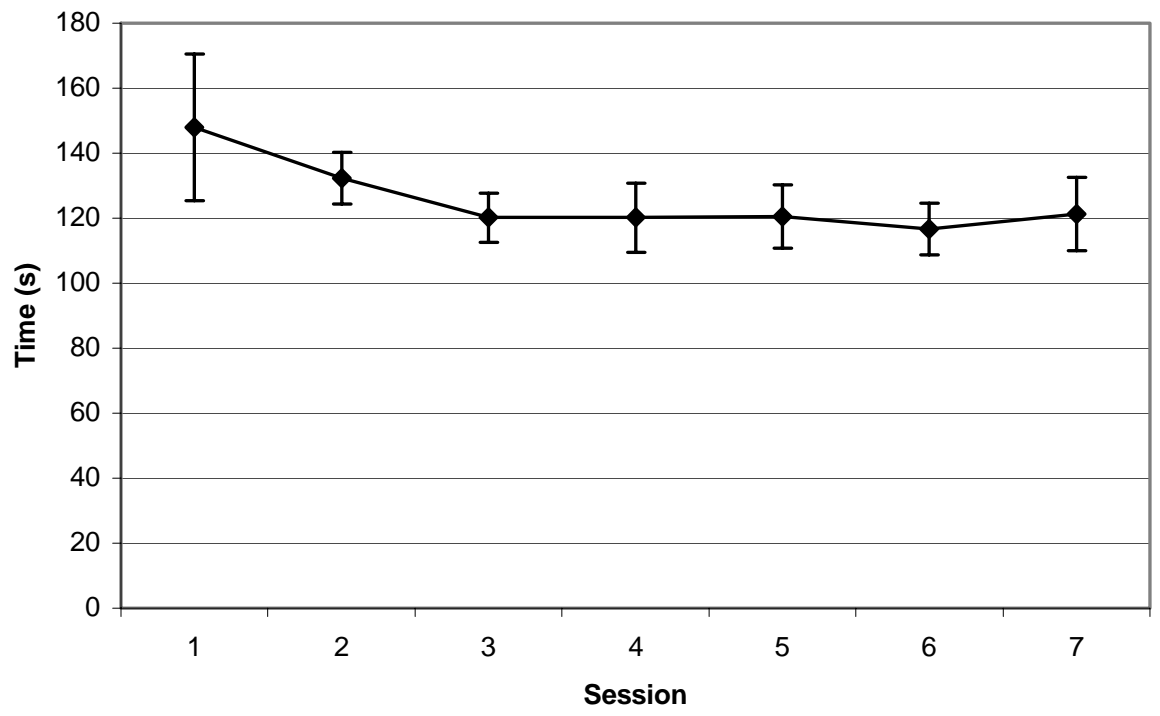

Figure 6. Task completion times in training sessions using the touch pad

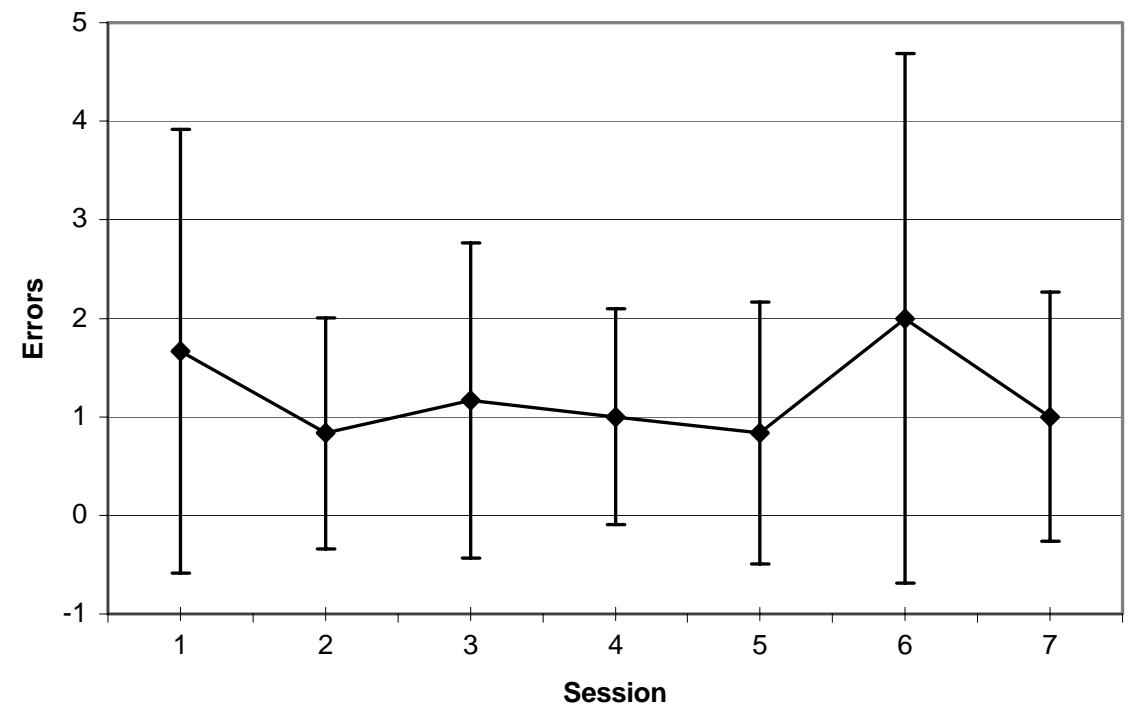

Figure 7. Number of errors in training sessions using the touch pad 


\subsection{Summary of Training Experiment}

Overall results based on the analysis of the training data for the mouse and touch pad indicate that participants became well practiced faster with the touch pad ( 3 sessions) than with the mouse ( 5 sessions). However, it appears that there may be some continued learning even after 5 training sessions, so in order to minimize the potential confounding of learning, six training sessions with each input device will be used for the formal experiment discussed in Chapter 6. 


\section{CHAPTER 5. DISPLAY-CONTROL GAIN EXPERIMENT}

\subsection{Experimental Goals}

The goal of the display-control (D-C) gain experiment was to determine the optimum gain setting for the mouse and touch pad input devices, so that an accurate analysis of input device performance could be made. D-C gain controls the velocity of the display cursor (Spencer, 2000), such that very high gain settings result in faster initial movements but fine positioning of the cursor is more difficult (Douglas \& Mithal, 1997). Findings from previous studies on the effects of D-C gain on input device performance are inconsistent (Epps, 1986; Buck, 1980). As a result, an experiment was conducted to determine the optimum D-C gain setting for the mouse and touch pad input devices. During the experiment, participants performed the text entry task with each input device at three gain settings. The D-C gain level that produced the best performance (i.e. fastest time and fewest errors) was used for the third experiment.

\subsection{Methodology}

\subsubsection{Participants}

The same participants were utilized for the training experiment and gain experiment. This experiment was conducted immediately following the training experiment.

\subsubsection{Experimental Task}

Participants performed six text entry tasks for this experiment. Each task consisted of 60 characters, but included different words and numbers than those used in the training experiment. The six tasks were presented in a random order. 


\subsubsection{Equipment}

The same equipment used in the training experiment was also used in the gain experiment.

\subsection{Experimental Design}

\subsubsection{Independent Variables}

A $2 \times 3$ within subjects design was used. Input device and gain were the independent variables. Treatment conditions were counterbalanced using a Balanced Latin Square Design in order to control for any potential practice or order effects (Table 2). Participants performed the text entry task with each device at three gain settings (Table 3).

Table 2. Gain experiment balanced Latin square design

\begin{tabular}{cccccc}
\hline \multicolumn{7}{c}{ Treatment Order } \\
O1 & O2 & O3 & O4 & O5 & O6 \\
\hline 1 & 2 & 3 & 4 & 5 & 6 \\
6 & 1 & 2 & 3 & 4 & 5 \\
2 & 3 & 4 & 5 & 6 & 1 \\
5 & 6 & 1 & 2 & 3 & 4 \\
3 & 4 & 5 & 6 & 1 & 2 \\
4 & 5 & 6 & 1 & 2 & 3 \\
\hline \multicolumn{7}{c}{ Treatments } \\
\hline 1 = mouse, gain = 1 \\
$2=$ touch pad, gain = 3 & $5=$ mouse, gain = 3 \\
$3=$ touch pad, gain = 1 & $6=$ mouse, gain = 2 \\
\hline \multicolumn{7}{c}{}
\end{tabular}

Table 3. Gain settings and definitions

\begin{tabular}{cc}
\hline Gain setting & Definition \\
\hline 1 & Slow gain \\
2 & Medium gain \\
3 & Fast gain \\
\hline
\end{tabular}




\subsubsection{Dependent Variables}

Task completion time and number of errors were the dependent variables. The same variable definitions used for the training study were also used in this experiment.

\subsection{Procedures}

Following completion of the training experiment, participants began the gain experiment. The input devices were attached to the forearm with a Velcro sleeve, and participants remained seated. Participants performed six text entry tasks: three with the mouse, and three with the touch pad. The D-C gain for each input device was changed by adjusting the cursor velocity (slow, medium, or fast) in the control panel of Windows $98 \AA$. Participants were instructed to perform the task as accurately as possible without sacrificing speed, and were told not to correct errors.

\subsection{Analysis}

Task completion time and number of errors were generated by the laptop computer. Task completion time, recorded in milliseconds, was converted to seconds for ease of analysis. In order to determine the optimum gain setting, the following decision criterion was used (Table 4). If the fastest task completion time and fewest errors were produced at the same D-C gain setting that setting was chosen as the optimum gain setting for that specific input device. However, if the fastest task completion time and fewest errors were produced at different D-C gain settings, a repeated measures ANOVA was performed to determine if there were significant differences in the number of errors committed. If differences were significant, the D-C gain setting that produced the fewest errors was chosen as the optimum gain setting. Otherwise, the D-C gain 
setting that produced the fastest task completion time was selected (consistent with procedures used in Spencer, 2000).

Table 4. Decision criteria for optimum gain

\begin{tabular}{ll}
\hline \multicolumn{1}{c}{ Condition } & \multicolumn{1}{c}{ Decision } \\
\hline $\begin{array}{l}\text { If same D-C gain level produced fastest } \\
\text { speed and fewest errors. }\end{array}$ & D-C gain setting optimum for that device. \\
& $\begin{array}{l}\text { Repeated measures analysis of variance: } \\
\text { If significant differences in number of errors, }\end{array}$ \\
$\begin{array}{ll}\text { If different D-C gain level produced } \\
\text { fastest speed and fewest errors. }\end{array}$ & $\begin{array}{l}\text { If gain setting with fewest errors chosen. } \\
\text { If no sificant differences in number of } \\
\text { errors, D-C gain setting that yielded fastest } \\
\text { task completion time chosen. }\end{array}$ \\
\hline
\end{tabular}

\subsection{Results}

\subsubsection{Mouse}

Gains of two and three resulted in the fewest errors (Table 5). Mean task completion time was the shortest for a D-C gain setting of two and longest for a gain setting of three (Table 6). Since the fewest number of errors and the shortest completion time were obtained at the same D-C gain level, no further analysis was necessary, and a D-C gain of two was selected as the optimum gain setting for the mouse.

Table 5. Mouse error data

\begin{tabular}{cccc}
\hline Gain & N & Mean Errors & Std. Dev. \\
\hline 1 & 6 & 1.00 & 1.67 \\
2 & 6 & 0 & 0 \\
3 & 6 & 0 & 0 \\
\hline
\end{tabular}

Table 6. Mouse task completion time data

\begin{tabular}{cccc}
\hline Gain & N & Mean Time & Std. Dev. \\
\hline 1 & 6 & 175.70 & 24.55 \\
2 & 6 & 173.82 & 21.33 \\
3 & 6 & 183.92 & 36.09 \\
\hline
\end{tabular}




\subsubsection{Touch pad}

A gain of two resulted in the fewest errors (Table 7). More errors resulted from gains of one and three. Mean task completion time was the shortest for a D-C gain of two and longest for a gain of one (Table 8). Since the fewest number of errors and the shortest completion time were obtained at the same D-C gain level, no further analysis is necessary, and a D-C gain of two was selected as the optimum gain setting for the touch pad.

Table 7. Touch pad error data

\begin{tabular}{cccc}
\hline Gain & N & Mean Errors & Std. Dev. \\
\hline 1 & 6 & 2.33 & 3.61 \\
2 & 6 & 0.33 & 0.52 \\
3 & 6 & 0.67 & 1.21 \\
\hline
\end{tabular}

Table 8. Touch pad task completion time data

\begin{tabular}{cccc}
\hline Gain & $\mathrm{N}$ & Mean Errors & Std. Dev. \\
\hline 1 & 6 & 145.22 & 22.30 \\
2 & 6 & 112.60 & 11.00 \\
3 & 6 & 140.10 .06 & 10.06 \\
\hline
\end{tabular}

\subsection{Summary of Gain Experiment}

After evaluating the data according to the decision criteria, a D-C gain of two was selected for subsequent experimentation using both devices. 


\section{CHAPTER 6. INPUT DEVICE EXPERIMENT}

\subsection{Experimental Goals}

The experimental methodology was designed in order to achieve the research objectives stated earlier. In review, the focus of this research was to determine which input device (mouse or touch pad) is better suited for text entry when the user is wearing CPC, and to determine if wearing CPC affects input device preference. During the experiment, participants used the mouse and touch pad to perform a text entry task while barehanded, wearing chemical protective gloves, wearing a respirator, and wearing the gloves and respirator. Results were used to establish guidelines for wearable input devices that are compatible with chemical protective clothing.

\subsection{Methodology}

\subsubsection{Participants}

Due to resource constraints, sixteen participants were recruited for this experiment (Appendix A). Using sixteen participants also afforded the use of a Balanced Latin square to counterbalance the treatment conditions. Participants were required to have experience wearing chemical protective masks to minimize potential problems of claustrophobia or anxiety. As a result, laboratory technicians, with mask wear experience, from the U.S. Army Medical Research Institute of Chemical Defense (MRICD) were recruited for this experiment. All participants were males between the age of 20 and 48 years old, and met the visual acuity requirements of 20/30 corrected or uncorrected. Visual acuity was verified with a Titmus ${ }^{\circledR}$ vision tester. Each participant reported that their typing skills were average $(40 \mathrm{wpm})$ or better, and all participants were right handed. A coding scheme was utilized to identify the data by participant number only 
(i.e. Subject 1) to maintain anonymity. All participants read and signed a Volunteer Agreement Affidavit (Appendix B) and completed informed consent procedures approved by the Virginia Tech Institutional Review Board (IRB).

\subsubsection{Experimental Task}

For this experiment, participants performed 22 text entry tasks: six for the training session, and 16 for the actual experiment. As in the training and gain experiments, each task consisted of entering 60 characters: 8 numbers and 41 letters, and 11 spaces. Tasks were presented in a random order, and scored using a Visual Basic program.

\subsubsection{Equipment}

The laptop computer, HMD, input devices, and On-screen keyboard used for the training and gain experiments were used for this experiment, with the addition of the chemical protective gloves and jacket, a respirator, and an input device questionnaire. Four glove thicknesses were used: 0 mil (bare hand), 7-mil $(0.178 \mathrm{~mm}), 14-\mathrm{mil}(0.356 \mathrm{~mm})$, and 25 -mil $(0.635 \mathrm{~mm})$. These gloves were selected because they are the standard issue chemical protective gloves worn in the military and civilian sectors. Thin gloves (i.e. 7-mil) are worn by medical staff and electronic repair personnel, who perform tasks that require extreme tactility and/or sensitivity and will not expose the gloves to harsh treatment. Aviators, vehicle mechanics, and weapon crews who perform tasks that require tactility and sensitivity and who will not expose the gloves to harsh treatment use the 14-mil glove set. Use of the more durable 25-mil glove set is for soldiers who perform close combat tasks and other types of heavy labor (Department of the Army, 1992). Chemical protective gloves are worn in sets, consisting of an outer rubber glove for protection and a thin cotton liner for perspiration absorption (Figure 8) and are available in five sizes (extra- 
small, small, medium, large, and extra large). Proper glove fit for participants was determined through visual inspection.

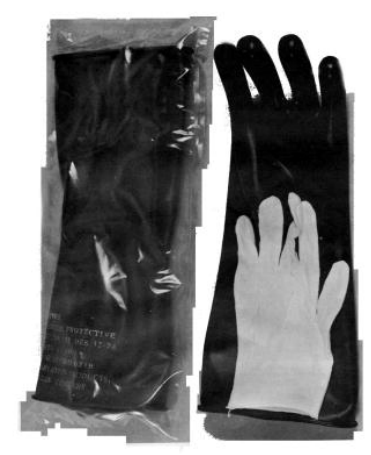

Figure 8. Chemical protective gloves and liner

Participants wore the standard issue chemical protective jacket during the study (Figure 9). The waist-length jacket provides protection against liquid and vapor agents, and is available in seven sizes from small-short, to large-long. Proper fit was determined using a standard sizing chart (Appendix C).

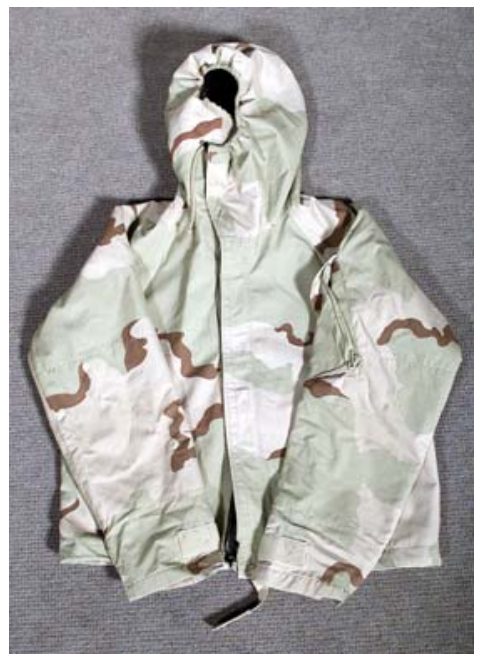

Figure 9. Chemical protective jacket 
A full face-piece respirator was used during the study because it is a standard issue respirator used in the military and civilian sectors (Figure 10). The respirator is available in three sizes: small, medium, and large and provides respiratory protection against nuclear, biological, and chemical threats by providing a barrier between the user and the environment and filtering air through an externally mounted canister. Participants were fitted with the respirator using a two-step procedure to ensure that the respirator was the correct size. First, a visual inspection will be performed (Appendix D). Second, a negative pressure check was performed. During this procedure, the participant places their hands over the air intake ports and breathes in. If the respirator sucks to the participant's face, it was sealed properly. If it did not, adjustments were made and the negative pressure check was performed again.

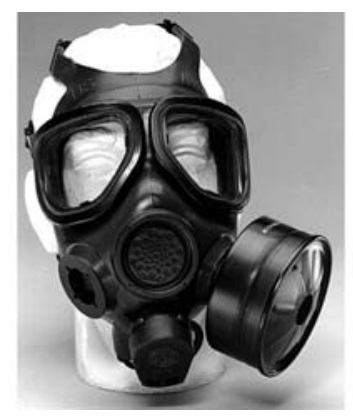

Figure 10. Full face-piece respirator

A questionnaire was developed to obtain participant opinions regarding the usability of the input devices (Appendix E). The questionnaire consisted of twenty-one items related to the ease of text entry, user confidence, and overall input device preference. Questions $1-16$ addressed how difficult it was to perform the text entry task for each of the treatment conditions. Questions 17-20 addressed user confidence when using the input devices to create and send message and navigate through menus during a military mission. Question 21 addressed input 
device preference. Participants rated each item using a Likert scale, which is an effective method for obtaining subjective data and is quick and easy to administer (Wilson \& Corlett, 1995).

\subsection{Experimental Design}

\subsubsection{Independent Variables}

A $4 \times 2 \times 2$ within subjects design was used, with three independent variables: glove thickness, respirator, and input device. Treatment conditions were counterbalanced using a Balanced Latin Square Design in order to control for any potential order effects. A within subjects design was chosen because of the more efficient use of subjects than between subjects designs. That is, within subjects designs allow use of fewer participants than a corresponding between or mixed-subjects design. A within subjects design also allowed each participant to become familiar with each input device when entering text and wearing the different components of chemical protective clothing, and thus be able to indicate any differences in preference for the input devices in each of the experimental conditions.

\subsubsection{Dependent Variables}

Two classes of dependent variables were used in the experiment: performance and subjective ratings. Performance variables were task completion time and number of errors. Subjective ratings were derived from the questionnaire responses. Task completion time and the number of errors helped determine which input device better facilitates accuracy, and which input device has faster completion times for each treatment condition. 


\subsection{Experimental Procedures}

Participants were seated at a table in an office and were given written instructions about the experiment. After reading the instructions, any questions were answered, and participants filled out a health and demographic questionnaire (Appendix F), which assessed the level of respirator wear experience, and the participants' current medical status.

A training session was conducted to help minimize the effects of learning and allow the participants to determine how the input devices respond when wearing the protective gloves. During the training, participants performed six text entry tasks with each input device, while wearing the 25-mil glove. Similar to the training and gain experiments, participants performed the text entry task while seated, and the input devices were mounted on the forearm with a Velcro® sleeve.

For the actual experiment, participants performed text entry for each of the treatment conditions. A five-minute break was given after eight sessions were completed. Participants were instructed to perform the text entry tasks as accurately as possible, without sacrificing speed. Accuracy was emphasized because, as mentioned previously, soldiers will use wearable computers to receive and transmit information that is critical to their survival and must be accurate. After completing the treatment conditions, participants filled out the questionnaire in which they rated the overall usability of each input device while wearing chemical protective clothing. Total time to complete the experiment was 2.5 hours. 


\subsection{Training Data Analysis}

An analysis of the task completion time and error data was performed in order to ensure that participants were well practiced with the input devices before beginning the experiment. Data from the first training session was considered practice, and was discarded. Prior to the statistical analysis of the training data, a correction, similar to the training experiment data, was applied to those trials where fewer than 60 characters were entered. An initial examination of the task completion time and error data for the mouse and touch pad indicated that these data did not follow a normal distribution. A reciprocal transformation of the task completion time data was done and these data were analyzed using a repeated measures ANOVA with $\alpha=.05$. Since the error data did not follow a normal distribution, a Friedman nonparametric ANOVA was performed, again with $\alpha=.05$. Significant effects were compared post hoc using pairwise comparisons with $\alpha=.05$.

\subsubsection{Mouse}

Training session was significant for task completion time, $F(5,75)=6.67, p<.0001$, with session 1 having a slower completion time than session $2, F(5,75)=9.70, p=.0071$. Session did not show significance for the error data, $F(5,75)=0.81, p=0.5441$. These results suggest that participants were well trained with the mouse before beginning the experiment, and that learning effects during the experiment were likely minimal (Figures 11 and 12). 


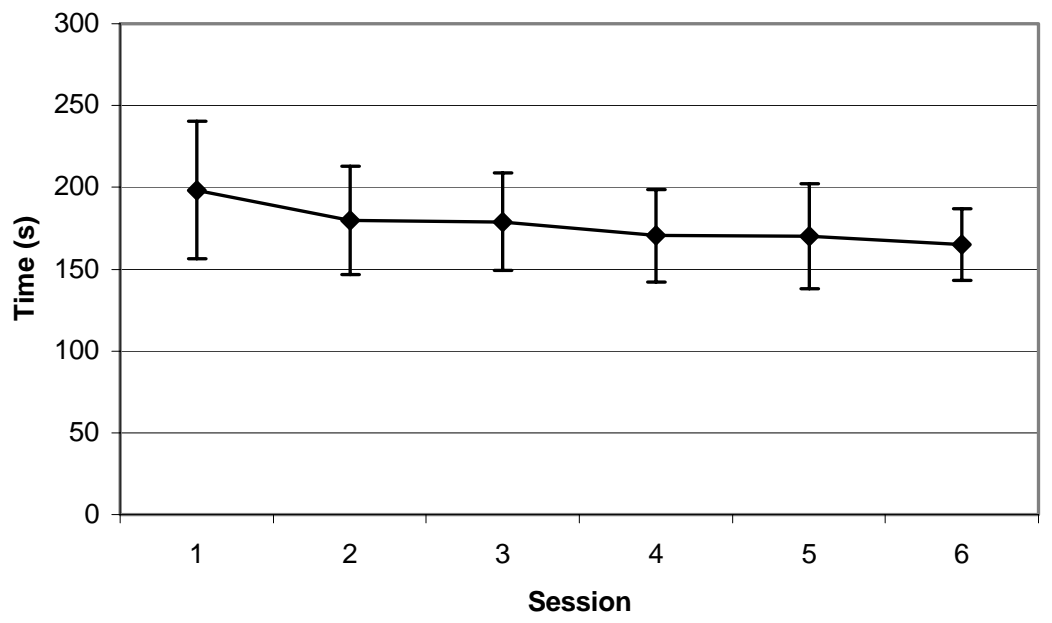

Figure 11. Task completion times for training sessions using the mouse

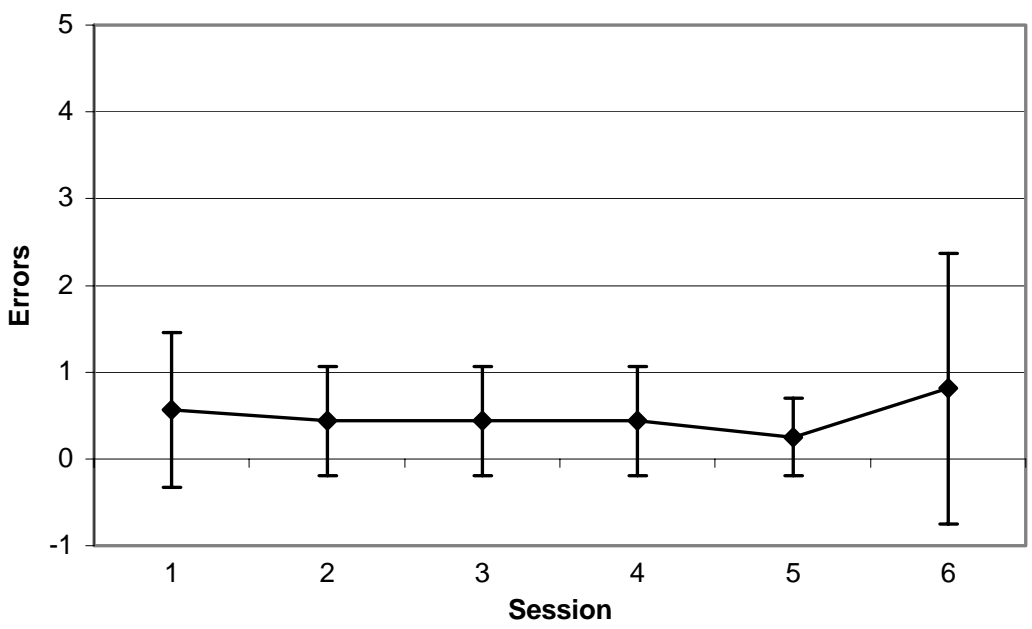

Figure 12. Number of errors in training session using the mouse

\subsubsection{Touch pad}

Training session was significant for task completion time, $F(5,75)=4.49, p=.0012$. Of the pairwise comparisons, only the difference between session 1 and sessions 3, 4, 5, and 6, were significant. While there were no significant differences between consecutive training sessions, 
task completion time gradually decreased across all training sessions, indicating that there may have been be some residual learning taking place (Figure 13). However, using the Latin square for counterbalancing should have minimized the likelihood of the residual learning as a confounding effect. Session did not have a significant effect on errors, $F(5,75)=0.54, p=$ 0.7476 (Figure 14).

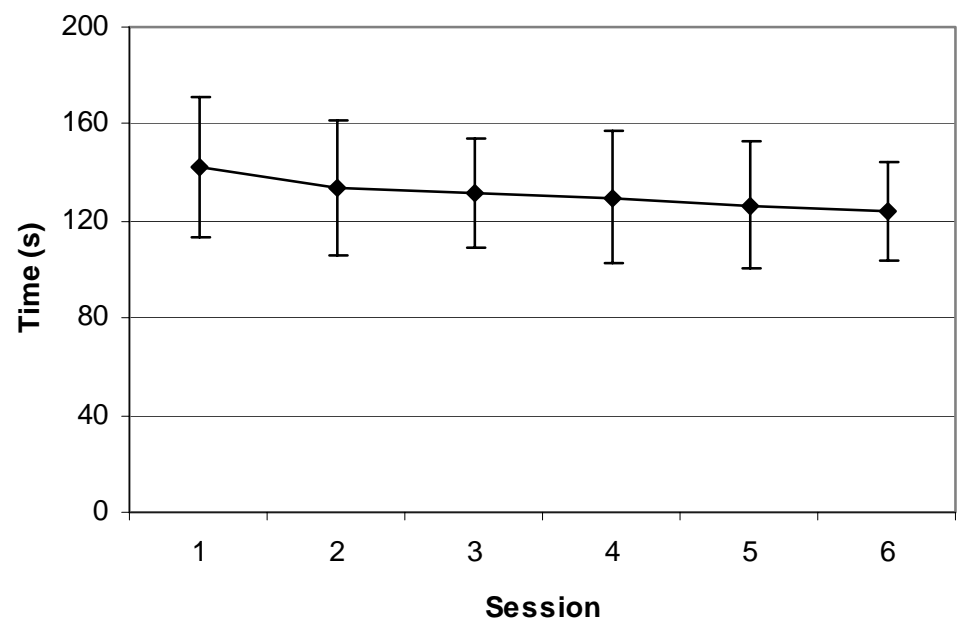

Figure 13. Task completion times for training sessions using the touch pad

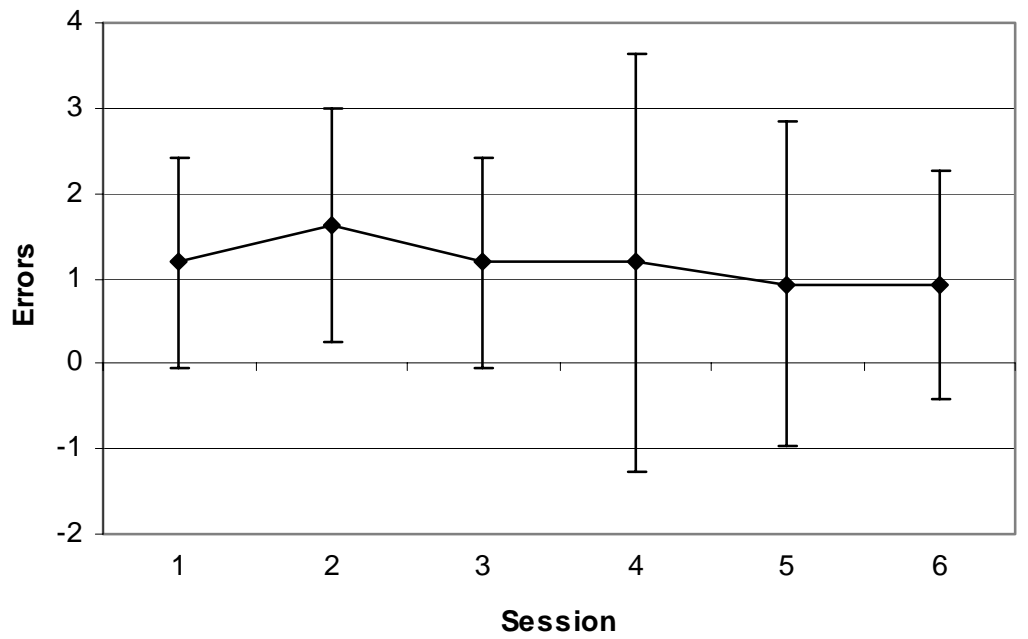

Figure 14. Number of errors in training sessions using the touch pad 


\subsection{Experimental Data Analysis}

Similar to the training data presented above, an examination of the experimental task completion time and error data for the mouse and touch pad was performed to examine the shape of the data distribution. Results indicate that the task completion time and error data did not follow a normal distribution, so a log transformation of the task completion time data was performed and these data were analyzed using a repeated measures ANOVA with $\alpha=.05$. Since the error data did not fit a specific distribution, a nonparametric ANOVA was performed, again with $\alpha=.05$. Tukey's HSD tests were used to compare significant effects. An examination of treatment order indicated that there was no significant order effect for task completion time $(p=0.980)$ or number of errors $(p=0.131)$.

Separate repeated measures ANOVAs were used to assess whether there are differences in participant responses to the difficulty, confidence, and preference questions. Since, each difficulty question corresponded to a treatment condition; data were coded by levels of device, mask, and glove. For the confidence questions, data was coded by task type: create and send messages, and navigate through menus. Preference data was coded by device. Significant effects were compared post-hoc using Tukey's HSD tests. Sphericity was examined using Mauchly's criterion. If data displayed a significant departure from sphericity, a Greenhouse-Geisser correction will be applied. 


\subsection{Results}

\subsubsection{Performance variables}

Device, $F(1,15)=24.24, p=.0002$, and glove thickness $F(3,45)=8.13, p=.0002$, had significant effects on task completion time. Neither respirator nor any factor interaction effects were significant. Of the pairwise comparisons, the touch pad yielded significantly shorter completion times than the mouse $(p<.0001)$, and the 7 -mil glove yielded shorter task completion times (Figure 15) than the 25-mil glove $(p=.0388)$. Neither device $(p=.1884)$, mask $(p=.1102)$, or glove $(p=.4493)$, nor any factor interactions had significant effects on the number of errors Mauchly's criterion was not significant for task completion time $(p=.980)$ or number of errors $(p=.455)$.

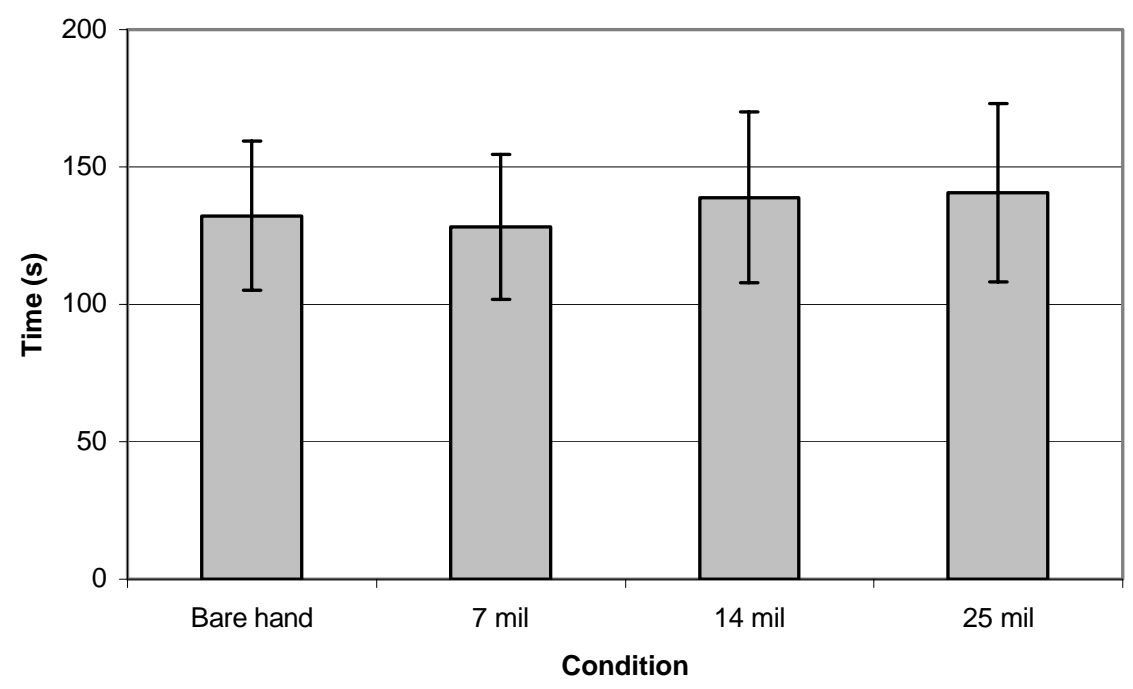

Figure 15. Task completion times for the four glove conditions 


\subsubsection{Subjective Ratings}

\subsubsection{Difficulty}

Device, $F(1,15)=18.86, p=0.0006$, and glove thickness, $F(3,45)=17.28, p<.0001$, had significant effects on perceived difficulty. The interaction between device and mask was also significant $(p=.0328)$. Neither mask nor any other factor interactions were significant. Mean (sd) responses were significantly higher for the mouse at 2.86 (1.08), than the touch pad at 2.04 (1.01), suggesting that participants thought the text entry task was slightly more difficult to perform with the mouse, than with the touch pad. Participants also reported that the text entry task was slightly more difficult to perform when wearing the 25 -mil glove, with mean (sd) responses for the 25 -mil glove at 3.14 (1.37), and were significantly higher than the bare hand at $2.0(0.89)$, the 7-mil glove at $2.14(0.87)$, and the 14-mil glove at $2.52(0.96)$. In addition, mean (sd) responses for the 14-mil glove at $2.52(0.96)$ were significantly higher compared to the bare hand condition at $2.0(0.89)$, showing that participants thought the text entry task was slightly more difficult when wearing the 14-mil glove, than when bare handed (Figure 16).

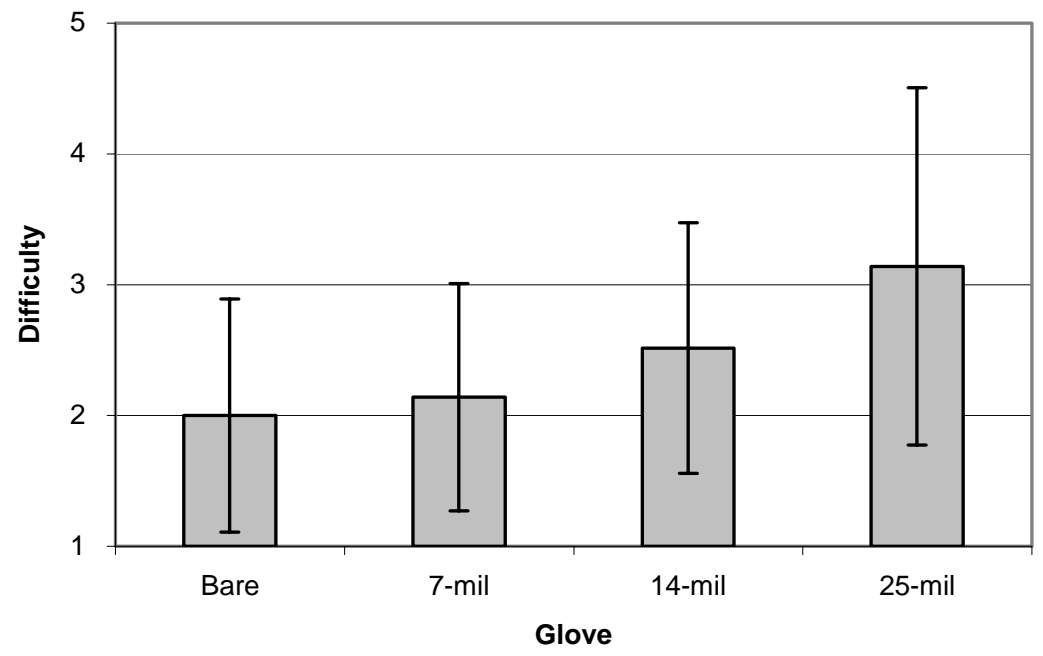

Figure 16. Perceived difficulty ratings by glove thickness 
For the device x mask interaction (figure 17), text entry for the mouse conditions (mask, no mask) was perceived as slightly more difficult than for the touch pad conditions (mask, no mask), with mean (sd) responses for mouse, no mask at 3.06 (1.13) and mouse, mask at 2.66 (1.01) significantly higher than touch pad, no mask at 2.05 (1.09) and touch pad mask at 2.03 (0.94).

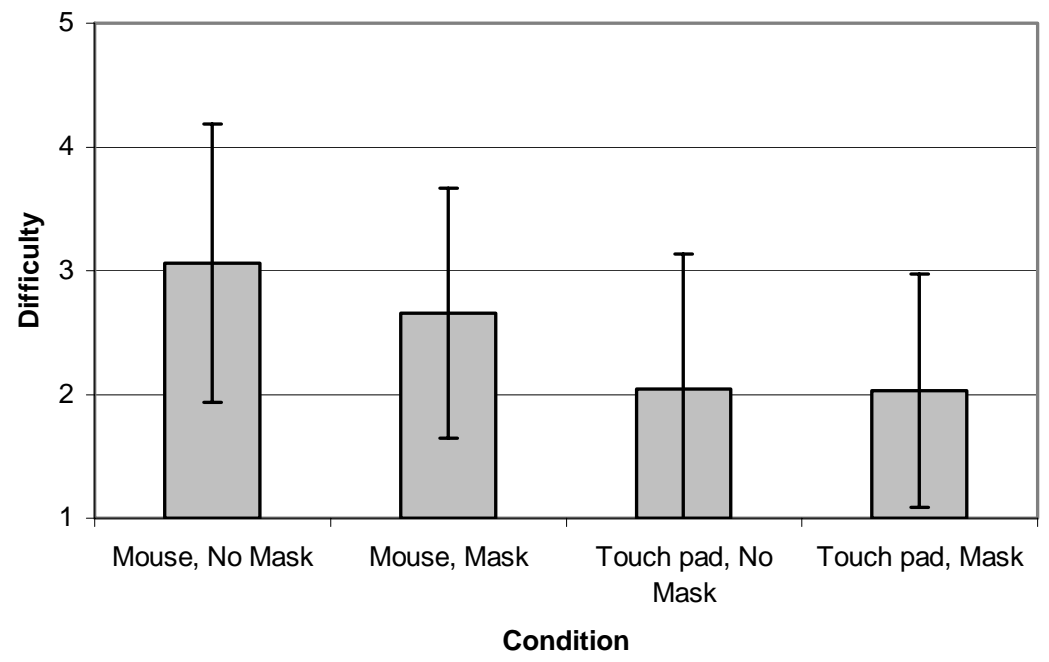

Figure 17. Interaction between device and mask

\subsubsection{Confidence}

Device had significant effects on perceived confidence when creating and sending messages, $F(1,30)=17.19, p=0.0003$, and navigating through menus, $F(1,30)=21.75, p<$ .0001 (Table 9). Participants agreed that they would feel confident using the touch pad to perform both tasks, but were neutral with respect to using the mouse to perform the tasks. 
Table 9. Mean confidence ratings

\begin{tabular}{ccc}
\hline & Mouse & Touch pad \\
Task & Mean (sd) & Mean (sd) \\
\hline Create and Send Messages & $2.94(1.48)$ & $4.56(0.51)$ \\
Navigate through Menus & $2.94(1.24)$ & $4.5(0.52)$ \\
\hline
\end{tabular}

\subsubsection{Input Device Preference}

All sixteen participants preferred the touch pad input device to the mouse, so no further statistical analysis was necessary. 


\section{CHAPTER 7. DISCUSSION}

Determining how chemical protective clothing affects task performance with wearable input devices is important in the design of wearable input devices and in the selection of compatible chemical protective clothing. The objectives of this research were to identify and quantify performance decrements that occur when wearing chemical protective clothing and use these results to develop recommendations for wearable input devices that are compatible with chemical protective clothing. In order to accomplish these objectives, several research questions were investigated. These questions will be discussed in light of previous research findings and those of the present study.

The first question addressed in this thesis was: what impact does wearing chemical protective gloves have on manipulation of wearable computer input devices? Since input devices for wearable computers will most likely be small and mounted on the body, wearing chemical protective gloves may make it difficult for users to manipulate the controls with their hand, thereby impacting task performance. Results here suggest that there is an apparent decrease in task performance with wearable input devices when wearing chemical protective gloves. For example, task completion time when wearing the 25 -mil gloves was $9 \%$ slower than when wearing the 7-mil gloves (Figure 15). These findings were similar to those of Bensel (1993), who reported that thick butyl rubber gloves impeded manual task performance when compared to bare hand performance, and performance times were $10 \%$ faster with thinner gloves than for thicker gloves.

One interesting observation is that when participants were bare handed, task completion time was slightly slower than when they wore the 7-mil glove, which is surprising because one 
would expect that wearing chemical protective clothing (i.e. gloves) would reduce speed, so task performance when bare handed should be better than with chemical protective gloves. A possible explanation is that the 7-mil gloves may provide a slightly better grip than wearing no glove at all, and since the 7-mil gloves are rather thin, they would not interfere with participants' ability to manipulate the input devices.

Questionnaire data are consistent with the performance measures. Participants reported that the text entry task was slightly more difficult to perform with the 25 -mil gloves than with the 7-mil and 14-mil gloves. Several participants commented that the 25-mil gloves made it difficult to move the cursor because they could not feel the indentation on the mouse where they would place their finger. In addition, using the mouse with the gloves, especially the 25 -mil gloves, increased the effort required to use the mouse input device. This increased effort may have resulted in fatigue, and therefore slower task completion times. Results of the performance measures and subjective ratings suggest that chemical protective gloves can be used with small, wearable input devices, however, as glove thickness increases, performance time decreases.

The second question addressed in this thesis was: what impact does wearing a chemical protective mask have on manipulation of wearable computer input devices? Earlier work (Bensel et al., 1987) has shown that wearing a chemical protective respirator can restrict the field-of-view, and thus may interfere with the wearer's ability to see the objects they are manipulating. However, in the present study, no significant differences in mean task completion time or mean errors were found when wearing the respirator. One possible reason for the inconsistency may be due to the type of task being performed. In the literature, tasks such as a pegboard task were used, that required participants to look down at the pegs, pick a peg up, and then place the peg on the pegboard, so they were constantly looking up and down. In the present 
research, all of the information was presented on the HMD, so participants only needed to look at the HMD to perform the text entry task.

Subjective data are consistent with the findings of the objective data. Participants reported that text entry while wearing the respirator was slightly more difficult when using the mouse, than when using the touch pad. Overall, participants commented that they did not think the mask interfered with their ability to perform the text entry task.

Third, what impact does wearing a chemical protective mask and gloves have on manipulation of wearable computer input devices? Wearing a full-face piece respirator has been shown to limit peripheral vision such that the wearer may experience a low-grade form of tunnel vision (Kobrick \& Sleeper, 1986). Gloves have also been shown to impair performance by limiting manual dexterity (Bensel, 1993; Plummer et al.; \& Johnson et al.), so it was hypothesized that the combination of chemical respirator and gloves would affect manipulation of input devices. However, data from the present study indicate that wearing the respirator and gloves had no significant affect on task completion time or errors. Performance with the gloves and mask was not significantly different from performance when wearing the gloves alone or when bare handed. For the questionnaire responses, participants reported that the text entry task was slightly more difficult to perform with respirator and gloves when using the mouse, than when using the touch pad.

Fourth, how much of the degradation in performance can be attributed to each of the components of chemical protective clothing? Data from the present research suggest that the decrement in task completion time was predominantly due to the wearing of the butyl rubber chemical protective gloves, since task performance was degraded to the same degree whether or not the participants wear the respirator while performing the task. Although previous research 
has shown that the gas mask impairs the wearer's vision, task performance with the mouse and touch pad input devices was not influenced by wearing the respirator. Similar findings were reported by King and Frelin (1984), who looked at the effects of different components of chemical protective clothing on performance of medical tasks and found that the decrements in performance were due to wearing the gloves, not the mask. Chemical protective gloves have been shown to decrease task performance as much as 30\% (Krueger et al., 1997), depending on glove thickness and type of task. When considering the mean task performance in the present study, wearing the 25 -mil gloves degraded performance by $9 \%$ compared to the 7 -mil glove for both the mouse and touch pad. Although the degradation is not as dramatic as that reported in the literature, the results provide some insight into how wearing the gloves impacts text entry with wearable input devices.

In summary, with regard to input device, the touch pad yielded a $17 \%$ faster task completion time than the mouse, with no significant differences in errors. Subjective data showed that participants would feel confident using the touch pad to create and send messages and navigate through menus, and all participants preferred the touch pad input device over the mouse. Results of this experiment would apply only to similar touch pad and mouse input devices. For example, touch pads that are capacitive in nature and mice with a similar configuration to the one used in this research. When considering the effects of chemical protective clothing, wearing the mask, and the combination of mask and gloves did not affect task performance, however, wearing the gloves lead to increased task completion time on the text entry task. It should be noted, that the results from this experiment are only generalizable to the butyl rubber chemical protective gloves included in this experiment. Additional research is 
necessary to determine if additional glove thicknesses and gloves made from other materials would have comparable effects on performance. 


\section{CHAPTER 8. CONCLUSIONS}

\subsection{Summary}

Wearable computers provide workers with the capability to perform their work anywhere, a capability that is not afforded with desktop computers. As a result, a wearable computer can be used in a variety of environments, including those that may require the user to wear chemical protective clothing. Chemical protective clothing can hinder manual dexterity, and as a result, may impact response time and accuracy when using wearable computer input devices. At present, protective gloves are designed with protection of the hand as the primary consideration, and the loss of dexterity due to the glove is either ignored or accepted as unavoidable. In addition, as mentioned previously, equipment developers have assumed that input devices designed and tested in non-hazardous environments are also suitable for use in hazardous environments. Based on the findings of the present study and earlier work, the following recommendations can be made.

\subsection{Recommendations}

1. A touch pad should be considered instead of a mouse-type input device. The touch pad was faster across all treatment conditions when performing the text entry task, and participants took less time to learn how to use the touch pad. In addition, participants felt confident using the touch pad, making it the device of choice for all participants.

2. Thin chemical protective gloves (i.e. 7-mil and 14-mil) are more suitable than thicker gloves for use with wearable input devices. Thick chemical protective gloves (i.e. 25-mil gloves) elicited slower task completion times and required more effort to perform the text entry task. 
3. Chemical protective respirators can be used to perform a text entry task with minimal decrements in task performance.

Findings of this research provide some useful guidelines for design and use of wearable input devices with chemical protective clothing. However, many issues still need to be addressed in order to ensure the compatibility of wearable input devices with protective clothing. These issues, as well as some of the limitations of the present research are discussed in the next two sections.

\subsection{Limitations}

The main goal of this research was to see how the various components of chemical protective clothing influence task performance with wearable input devices. A text entry task was chosen because it is a standard task done with both desktop and wearable computers, and would be familiar to the participants. It is unclear if the results from this research can be generalized to other tasks that would be performed with a wearable computer. For example, a menu-driven system or graphical user interface (GUI) would require the user to perform "drag and drop" operations, which may prove difficult to perform with a wearable input device, especially with a gloved hand. Additional research would help identify tasks that can be performed with wearable input devices and how each task is affected by wearing protective gloves. Results would also help influence the design of the user interface.

Research into gender differences in manual dexterity suggests that women tend to be more adept at finger dexterity (Anderson, 1987); however, only males participated in the present research, so it is unclear if the results would generalize to females as well. Wearable computer 
users will be both male and female, so it is important to understand how gender impacts task performance with wearable input devices.

The input device assessment questionnaire was given after participants had completed the experiment, which may have led to difficulty recalling trials performed early in the experiment. Treatment conditions were counterbalanced, so any recency effects were minimized. In addition, the gloves were so different from each other, and participants performed so many treatment conditions that it seems unlikely that participants would have trouble recalling the information. However, a better method may have been to have participants rate the difficulty immediately following the treatment condition, and then follow up with an overall assessment questionnaire at the end of the experiment, to obtain their opinion about confidence and preference.

\subsection{Future research}

In the present research, butyl rubber gloves were shown to influence task performance. Additional research should be conducted to determine if newer glove materials would provide an adequate level of protection without sacrificing dexterity. Optimum placement of wearable input devices on the body should be investigated further. Forearm placement worked for the purposes of this study; however, it is likely that wearable computer users will have additional equipment attached to their body, which may make forearm placement problematic. 


\section{REFERENCES}

Anderson, Nancy S. (1987). Cognition, Learning, and Memory. In M.A. Baker (Eds), Sex differences in human performance. New York: John Wiley and Sons.

Arad, M., Berkenstadt, H., Zelingher, J., Laor, A., Shermer, J., and Atsmon, J. (1993). The effects of continuous operation in a chemical protective ensemble on the performance of medical tasks in trauma management. Journal of Trauma, 35(5), 800-804.

Baber, C. (1997). Beyond the Desktop. San Diego, CA: Academic Press.

Bass, L., Mann, S., Siewiorek, D., and Thompson, C. (199\&). Issues in Wearable Computing. ACM SIGCHI Bulletin, 29(4), 34-39.

Barfield, W., and Baird, K. (1998). Issues in the Design and Use of Wearable Computers. Virtual Reality, 3, 157-166.

Bensel, C. K. (1980). A Human Factors Evaluation of Two Types of Rubber CB Protective Gloves (NATICK/TR-80/005). Natick, MA: U.S. Army Natick Research and Development Command.

Bensel, C. K., Teixeira, R.A., and Kaplan, D.B. (1987). The Effects of U.S. Army Chemical Protective Clothing on Speech Intelligibility, Visual Field, Body Mobility, and Psychomotor Coordination of Men (TR-87-037). Natick, MA: United States Army Natick Research, Development, and Engineering Center.

Bensel, C. K. (1993). The effects of various thicknesses of chemical protective gloves on manual dexterity. Ergonomics, 36(6), 687-696.

Bensel, C. K. (1997). Soldier performance and functionality: Impact of chemical protective clothing. Military Psychology, 9(4), 287-300.

Billinghurst, M., Bowskill, J., Dyer, N., and Morphett, J. (1998). An Evaluation of Wearable Information Spaces. Paper presented at the Virtual Reality Annual International Symposium.

Billinghurst, M., and Starner, T. (1999). Wearable Devices: New Ways to Manage Information. IEEE Computer, 32(1), 57-64.

Brletich, N. R., Tracy, M.F., and Dashiell, T.R. (1992). Worldwide NBC Mask Handbook. Edgewood, MD: Chemical Warfare/Chemical and Biological Defense Information Center.

Buck, L. (1980). Motor Performance in Relation to Control-Display Gain and Target Width. Ergonomics, 23, 579-589. 
Caldwell, J. L., Caldwell, J.A., and Salter, C.A. (1997). Effects of Chemical Protective Clothing and Heat Stress on Army Helicopter Pilot Performance. Military Psychology, 9(4), 315328.

Calhoun, G. L., and McMillan, G.R. (1998, March). Hands-Free Input Devices for Wearable Computers. Paper presented at the Proceedings of the Fourth Annual Symposium of Human Interaction with Complex Systems, Dayton, OH.

Card, S. K., English, W., and Burr, B. (1978). Evaluation of mouse, rate-controlled isometric joystick, step keys and text keys for text selection on a CRT. Ergonomics, 21, 601-613.

Cleveland, G. and McNinch, L. (1999). Force XXI Land Warrior: Implementing Spoken Commands for Soldier Wearable Systems. Paper presented at the International Symposium on Wearable Computers, San Francisco, CA.

Coates, M. J., Jundi, A.S., and James M.R. (2000). Chemical Protective Clothing; A Study Into the Ability of Staff to Perform Lifesaving Procedures. Journal of Accident and Emergency Medicine, 17, 115-118.

Douglas, S., and Mithal, A. (1997). The Ergonomics of Computer Pointing Devices. New York: Springer-Verlag.

Durlach, N., and Mavor, A. (Eds.). (1995). Virtual Reality Scientific and Technical Challenges. Washington, D.C.: National Academy Press.

Epps, B. (1986). A Comparison of Cursor Control Devices on Target Acquisition, Text Editing, and Graphics Tasks. Unpublished Dissertation, Virginia Polytechnic Institute and State University, Blacksburg, VA.

Headley, D. B., and Hudgens, G.A. (1997). The impact of chemical protective clothing on military operational performance. Military Psychology, 9(4), 359-374.

Johnson, R. F. and Sleeper, L.A. (1986). Effects of chemical protective handwear and headgear on manual dexterity. Proceedings of the Human Factors and Ergonomics Society, 30, 994-997.

Kobrick, J.L., and Sleeper, L.A. (1986). Effect of wearing chemical protective clothing in the heat on signal detection over the visual field. Aviation, Space, and Environmental Medicine, 57, 144-148.

King, J.M., and Frelin, A.J. (1984). Impact of the chemical protective ensemble on the performance of basic medical tasks. Military Medicine, 149, 496-501.

Krueger, G. P., and Banderet, L.E. (1997). Effects of chemical protective clothing on military performance: A review of the issues. Military Psychology, 9(4), 255-286. 
Krausman, A., Boynton, A., Harper, W., Ortega, S., and Wilson, R. (2002). Human Factors Evaluation of Land Warrior Version 1.0. (Rep. No. ARL-TR-3205). Aberdeen Proving Ground, MD: U.S. Army Research Laboratory.

McMillan, G., Calhoun, G., Masquelier, B.L., Grigsby, S., Quill, L.L., Kancler, D.E., and Revels, A.R. (1999). Comparison of Hands-free versus Conventional Wearable Computer Control for Maintenance Applications. Proceedings of the Human Factors and Ergonomics Society, 43, 1036-1040.

Middlebrooks, S., and Spencer, R.A. (2000). Evaluation of Selected Visual Displays for Text Entry and Numerical Manipulation with Wearable Computers.

Milner, N. (1988). A Review of Human Performance and Preferences with Different Input Devices to Computer Systems, The British Computer Society Human-Computer Interaction Specialist Group. University of Manchester: Cambridge University Press.

Neter, J., Kutner, M.H., Nachtsheim, C.J., and Wasserman, W. (1996). Applied Linear Statistical Models (Fourth ed.). Boston, Massachusetts: McGraw-Hill.

Oborne, D. (1995). Ergonomics at Work. West Sussex, England: John Wiley and Sons, Ltd.

O'Hern, M. R., Dashiell, T.R., and Tracy, M.F. (1997). Chemical Defense Equipment. In F. R. Sidell, Takafuj, E.T., and Franz, D.R. (Ed.), Textbook of Military Medicine: Medical Aspects of Chemical and Biological Warfare (pp. 361-396). Washington, DC: Department of the Army.

Plummer, R., Stobbe, T., Ronk, R., Myers, W., Kim, H., and Jaraiedi, M. (1985). Manual Dexterity Evaluation of Gloves Used in Handling Hazardous Materials. Paper presented at the Proceedings of the Human Factors and Ergonomics Society 29th Annual Meeting, Santa Monica, CA.

Robinette, K. M., Ervin, C., and Zehner, G.F. (1986). Dexterity Testing of Chemical Defense Gloves (AAMRL-TR-86-021). Wright Patterson Air Force Base, OH: Harry G. Armstrong Aerospace Medical Research Laboratory.

Siegel, J., Kraut, R., John, B., and Carley, K. (1995). Empirical Study of Collaborative Wearable Computer Systems. Paper presented at the Human Factors in Computing Systems, Denver, CO.

Spencer, R. A. (2000). Analysis of Performance Resulting from the Design of Selected Hand Held Input Control Devices and Visual Displays. Unpublished Master Thesis, Virginia Polytechnic Institute and State University, Blacksburg.

Thomas, B., Tyerman, S., and Grimmer, K. (1997). Evaluation of Three Input Mechanisms for Wearable Computers. Paper presented at the International Symposium on Wearable 
Computers, Cambridge, MA.

Thomas, B., Grimmer, K., Makovec, D., Zucco, J., and Gunther, B. (1999). Determination of Placement of a Body-Attached Mouse as a Pointing Device for Wearable Computers. Paper presented at the International Symposium on Wearable Computers, San Francisco, CA.

Thorndike, E.L. and Lorge, I. (1944). The Teacher's Word Book of 30,000 Words. Teachers College, Columbia University, New York.

USDA. (1996). NBC Protection (FM 3-4). Washington, DC.

USDOT. (1994). Unit Maintenance Manual (Including Repair Parts and Special Tools List) For Chemical-Biological, Mask: Field M40. Washington, DC.

USGAO. (December 1999). Battlefield Automation (GAO/NSIAD-00-28). Washington, D.C.: United States General Accounting Office.

Weiland, W. J., Zachary, W. W., and Stokes, J.M. (2000). Personal Wearable Computer Systems. Paper presented at the IEA 2000/HFES 2000 Congress, Santa Monica, CA.

White, M. K., Hodous, T.K., and Vercruyssen, M. (1991). Effects of Thermal Environment and Chemical Protective Clothing on Work Tolerance, Physiological Responses, and Subjective Ratings. Ergonomics, 34, 445-457.

Wilson, J.R., and Corlett, E.N. (1995). Evaluation of Human Work. London: Taylor \& Francis.

Winer, B. J., Brown, D.R., and K.M. Michels. (1991). Statistical Principles in Experimental Design. New York: McGraw-Hill. 


\section{APPENDICES}


APPENDIX A. POWER CALCULATIONS 
Sixteen participants will be used in the proposed experiment, due to a limited number of volunteers and the amount of time required for each participant to complete the experiment. In addition, using sixteen participants affords the use of a balanced Latin square to counterbalance the treatment conditions.

Given the fact that only sixteen participants are available to participate in the experiment, a power analysis was performed to estimate the statistical power for detecting differences, and determining whether these differences are adequate. Data from a field test performed at Aberdeen Proving Ground, Maryland in March 2002 will be used in the power estimate. The purpose of the field test was to evaluate performance of a text entry task with a chest mouse input device while wearing three gloves of various thickness and materials including a leather utility glove, a trigger finger mitten, and a $25 \mathrm{~mm}$ butyl rubber glove. Task completion time and errors were measured. For the butyl rubber glove condition, a mean task completion time of 156.8 seconds, with a range of $113.5-219.7$, and a standard deviation of $\sim 34$ seconds was reported. Task completion time data from the butyl rubber glove condition in the Land Warrior field test and a procedure outline in Neter, Kutner, Nachtsheim, and Wasserman (1996) will be used to perform the power estimate for the proposed experiment.

Neter, Kutner, Nachtsheim, and Wasserman (1996) use Table B.12 in order to estimate power for a given sample size. Parameters used in the table include an estimate of the range specified in units of the standard deviation, $\alpha$, and $r$, which is the number of factor levels for a given variable. For the proposed study, when using a sample size of 16 , we can estimate a response time of 34 seconds ( 1 standard deviation) with power less than .70 ( $\alpha=.05, r=4$ gloves). We would need at least 19 participants in order to have a power of .70. However, we 
can estimate a response time of 43 seconds (1.25 standard deviations) with power of $.80(\alpha=.05$, $\mathrm{r}=4$ gloves) with fifteen participants. Therefore, sixteen subjects will enable us to be able to detect a difference of 43 seconds between mean task completion times with a power slightly greater than .80 , which is adequate for a military application. 
APPENDIX B. VOLUNTEER AGREEMENT AFFADAVIT 
VOLUNTEER AGREEMENT AFFIDAVIT:

ARL-HRED Local Adaptation of DA Form 5303-R. For use of this form, see AR 70-25 or AR 40-38

The proponent for this research is:

\section{U.S. Army Research Laboratory \\ Human Research and Engineering Directorate \\ Aberdeen Proving Ground, MD 21005}

\begin{tabular}{|c|c|}
\hline Authority: & $\begin{array}{l}\text { Privacy Act of 1974, } 10 \text { U.S.C. 3013, [Subject to the authority, direction, and control of the } \\
\text { Secretary of Defense and subject to the provisions of chapter } 6 \text { of this title, the Secretary of the } \\
\text { Army is responsible for, and has the authority necessary to conduct, all affairs of the Department of } \\
\text { the Army, including the following functions: (4) Equipping (including research and development), } \\
44 \text { USC } 3101 \text { [The head of each Federal agency shall make and preserve records containing } \\
\text { adequate and proper documentation of the organization, functions, policies, decisions, procedures, } \\
\text { and essential transactions of the agency and designed to furnish the information necessary to protect } \\
\text { the legal and financial rights of the Government and of persons directly affected by the agency's } \\
\text { activities] }\end{array}$ \\
\hline Principal purpose: & To document voluntary participation in the Research program. \\
\hline Routine Uses: & $\begin{array}{l}\text { The SSN and home address will be used for identification and locating purposes. Information } \\
\text { derived from the project will be used for documentation, adjudication of claims, and mandatory } \\
\text { reporting of medical conditions as required by law. Information may be furnished to Federal, State, } \\
\text { and local agencies. }\end{array}$ \\
\hline Disclosure: & $\begin{array}{l}\text { The furnishing of your SSN and home address is mandatory and necessary to provide identification } \\
\text { and to contact you if future information indicates that your health may be adversely affected. } \\
\text { Failure to provide the information may preclude your voluntary participation in this data collection. }\end{array}$ \\
\hline
\end{tabular}

Part A • Volunteer agreement affidavit for subjects in approved Department of Army research projects

Note: Volunteers are authorized medical care for any injury or disease that is the direct result of participating in this project (under the provisions of AR 40-38 and AR 70-25).

\begin{tabular}{|c|l|l|}
\hline Title of Research Project: & $\begin{array}{l}\text { Effects of Wearing Chemical Protective Clothing on Task Performance Using Wearable Input } \\
\text { Devices }\end{array}$ \\
\hline Human Use Protocol Log Number: & ARL-20098-020XX & Phone: 410-278-5933 \\
& E-Mail: ahynes@arl.army.mil \\
Principal Investigator: & $\begin{array}{l}\text { Andrea S. Krausman, } \\
\text { Uuman Research and Engineering Directorate }\end{array}$ & $\begin{array}{l}\text { Hurmy Research Laboratory } \\
\text { Associate Investigator(s) }\end{array}$ \\
\hline Location of Research: & $\begin{array}{l}\text { U.S. Army Research Laboratory, APG, MD } \\
\text { Soldier Biological and Chemical Command, Edgewood, APG, MD }\end{array}$ \\
\hline Dates of Participation: & November 2002 - February 2003 \\
\hline
\end{tabular}


Part B - To be completed by the Principal Investigator

Note: Instruction for elements of the informed consent provided as detailed explanation in accordance with Appendix C, AR 40-38 or AR 70-25.

\section{Purpose of the Research}

You are invited to participate in a study designed to evaluate the usability of wearable input devices. These devices have been developed for use with small, portable computers, often called wearable computers and allow a wearable computer user to select and manipulate objects, enter data, and navigate through menus. The primary purpose of this study is to determine how wearing chemical protective clothing affects task performance when using wearable input devices. This study is being conducted by the Army Research Laboratory (ARL) - Human Research Engineering Directorate (HRED).

\section{Procedures}

You will be assigned a participant number and receive a vision screening to ensure that you have 20/30 vision (corrected or uncorrected). Prior to beginning the experiment, you will receive a training session on how to use the two input devices that will be mounted on your forearm: a mouse and a touch pad. These devices have been developed for use with wearable computers. You will been given time to practice using the input devices to perform a text entry task, in which you will enter various words and numbers into a wearable computer. In addition, you will be fitted with a chemical protective mask and gloves, which you will wear during the experiment. Proper glove size will be determined through visual inspection by Army Research Laboratory personnel. Proper mask fit will be determined by (1) a visual inspection and (2) a negative pressure check.

After you are properly fitted with the mask and gloves and are familiar with the two input devices, you will begin the experiment. During the experiment, you will wear a helmet-mounted display, which will take the place of a computer monitor. You will perform sixteen text entry tasks using the mouse and touch pad input devices. You will perform the text entry task (1) while barehanded (2) while barehanded and wearing a chemical mask (3) while wearing a 7-mil, 14-mil, and 25 mil chemical protective glove and (4) wearing the chemical protective gloves and mask together. You will remain seated for the duration of the experiment. After you complete the experiment, you will fill out a questionnaire designed to solicit your opinion about the input devices. The entire experiment will take approximately 2.5 hours to complete.

\section{Benefits}

You will receive no benefits from participating in the project, other than the personal satisfaction of supporting the development of wearable computer systems that are compatible with chemical protective clothing.

\section{Risks}

Risks associated with this study are minimal and typical of the everyday risks encountered by people using a desktop computer. Several precautions will be taken to ensure that the equipment used in this experiment is carefully cleaned. The chemical protective masks and input devices will be thoroughly cleaned with alcohol before the experiment begins and the cotton liners worn underneath the chemical protective gloves will be thrown away after you complete the experiment.

\section{Confidentiality}

All data and information obtained about you will be considered privileged and held in confidence. Photographic or video images of you taken during this data collection will not be identified with any of your personal information (name, rank, or status). Complete confidentiality cannot be promised, particularly if you are a military service member, because information bearing on your health may be required to be reported to appropriate medical or command authorities. In addition, applicable regulations note the possibility that the U.S. Army Medical Research and Materiel Command (MRMC-RCQ) officials may inspect the records.

\section{Disposition of Volunteer Agreement Affidavit}

The Principal Investigator will retain the original signed Volunteer Agreement Affidavit and forward a photocopy of it to the Chair of the Human Use Committee after the data collection. The Principal Investigator will provide a copy of the signed and initialed Affidavit to you.

\section{Contacts for Additional Assistance}

If you have questions concerning your rights on research-related injury, or if you have any complaints about your treatment while participating in this research, you can contact: 
Chair, Human Use Committee

U.S. Army Research Laboratory

Human Research and Engineering Directorate

Aberdeen Proving Ground, MD 21005

(410) 278-0612 or (DSN) 298-0612
OR Office of the Chief Counsel

\author{
U.S. Army Research Laboratory \\ 2800 Powder Mill Road \\ Adelphi, MD 20783-1197 \\ (301) 394-1070 or (DSN) 290-1070
}

I do hereby volunteer to participate in the research project described in this document. I have full capacity to consent and have attained my 18th birthday. The implications of my voluntary participation, duration, and purpose of the research project, the methods and means by which it is to be conducted, and the inconveniences and hazards that may reasonably be expected have been explained to me. I have been given an opportunity to ask questions concerning this research project. Any such questions were answered to my full and complete satisfaction. Should any further questions arise concerning my rights or project related injury, I may contact the ARL-HRED Human Use Committee Chairperson at Aberdeen Proving Ground, Maryland, USA by telephone at 410-278-0612 or DSN 298-0612. I understand that any published data will not reveal my identity. If I choose not to participate, or later wish to withdraw from any portion of it, I may do so without penalty. I understand that military personnel are not subject to punishment under the Uniform Code of Military Justice for choosing not to take part as human volunteers and that no administrative sanctions can be given me for choosing not to participate. I may at any time during the course of the project revoke my consent and withdraw without penalty or loss of benefits. However, I may be required (military volunteer) or requested (civilian volunteer) to undergo certain examinations if, in the opinion of an attending physician, such examinations are necessary for my health and well being.

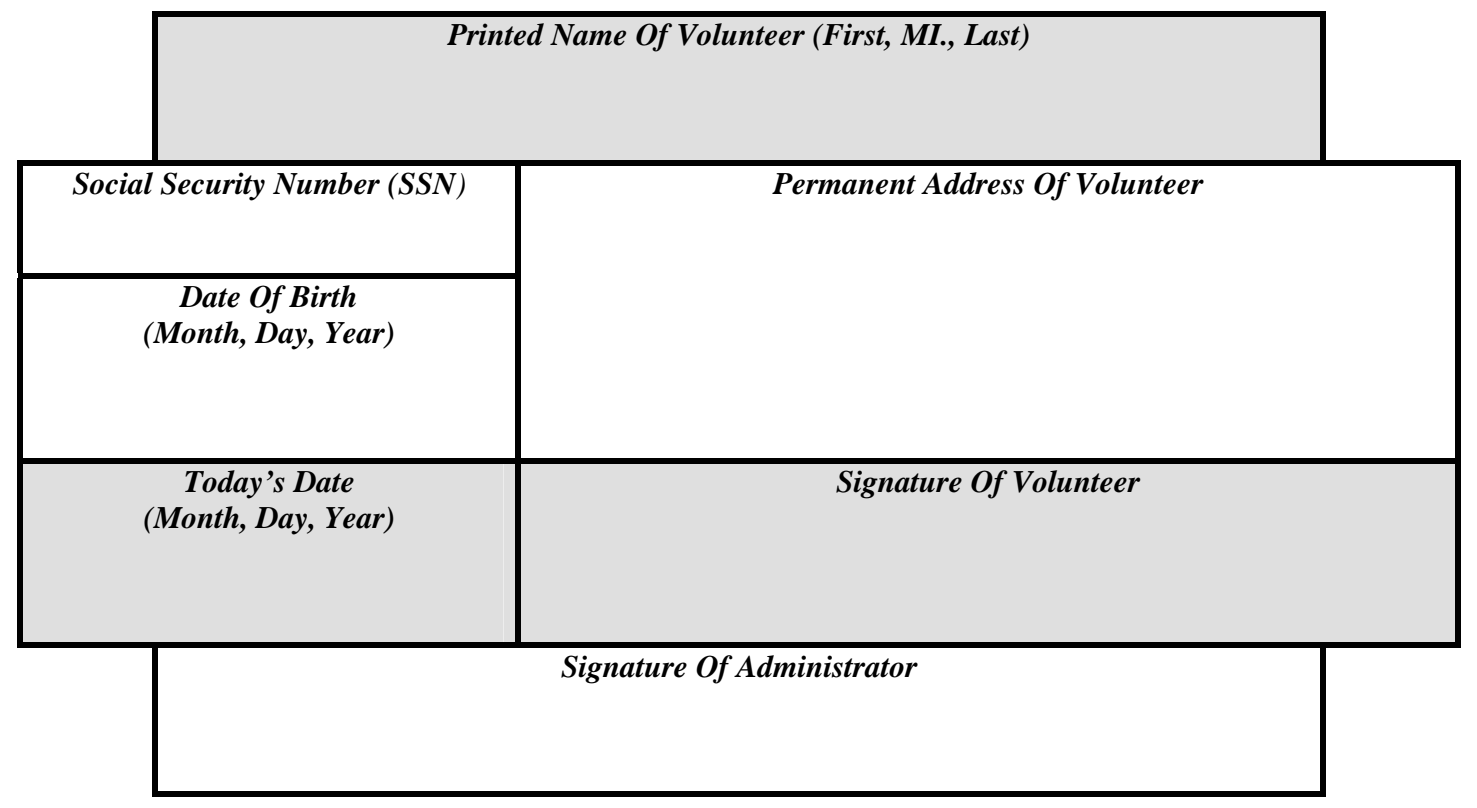


APPENDIX C. CHEMICAL PROTECTIVE JACKET SIZING CHART 


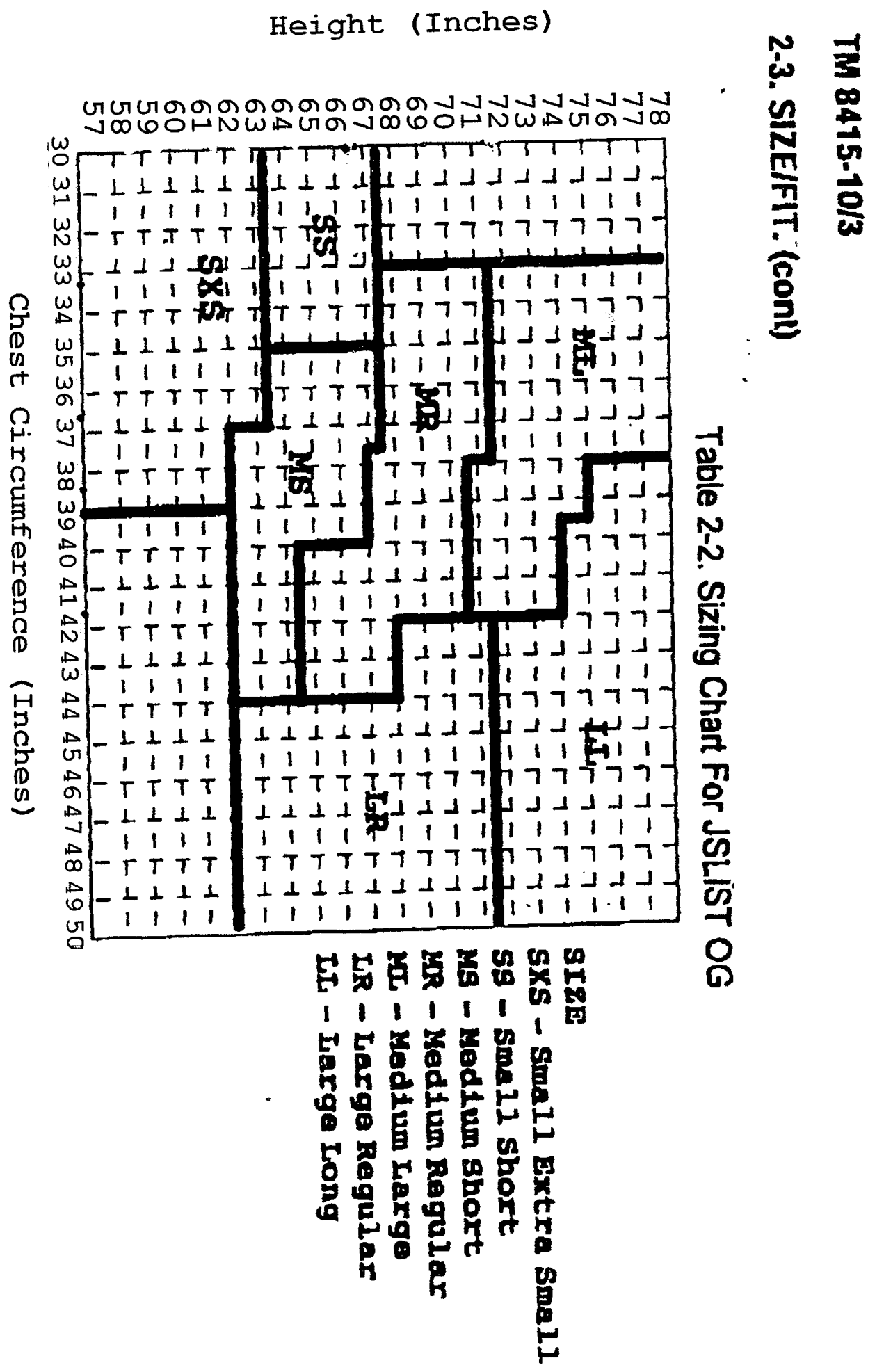


APPENDIX D. RESPIRATOR FIT CRITERIA 


\section{CRITERIA FOR PROPER RESPIRATOR FIT (If facepiece does not meet the following standards, try another mask)}

- Check the edge of the facepiece to make sure it comes well up on the forehead, but not more than one half inch into hairline, and within 1 inch of the ear.

- Have soldier slip head harness over head while holding facepiece against face.

- Center head harness pad on back of soldier's head and have soldier hold in place.

- Check that temple straps and cheek straps do not cut into soldier's ears.

- Soldier's pupils are in the top half of the eye lens.

- Bottom of facepiece does not cut into throat.

- Nose cup sits as high as possible on bridge of nose

- Place finger or thumb under buckle of forehead strap. Then give a sharp tug until buckle feels snug. Adjust the other forehead strap in same manner.

- Adjust cheek straps.

- Pull out both jaw tabs approximately 2 inches to properly seat mask on face.

- Have soldier release face piece. Face piece should not slip down. If face piece slips, readjust forehead and cheek straps until face piece remains in place.

- Adjust temple straps.

- If face piece is difficult to fit but meets most of the criteria, try a different size nose cup.

- Check fit again (different size nose cup will affect the position of the nose cup on the nose and the position of the facepiece on the face).

- If face piece still does not fit, check with a different size face piece.

- For comfort, resize nose cup/facepiece.

adapted from USDA TM 3-4240-300-20\&P 
APPENDIX E. INPUT DEVICE QUESTIONNAIRE 


\section{APPENDIX E: INPUT DEVICE ASSESSMENT Participant Number:}

Please read each item carefully. Indicate your opinion by placing an $\mathrm{X}$ in the response boxes below.

\begin{tabular}{|c|c|c|c|c|c|}
\hline Question & & & Response & & \\
\hline $\begin{array}{l}\text { 1. When BAREHANDED, the text } \\
\text { entry task was difficult to perform } \\
\text { with the MOUSE. }\end{array}$ & $\begin{array}{c}\text { Strongly Disagree } \\
\square\end{array}$ & Disagree & $\begin{array}{l}\text { Neither Agree Nor } \\
\text { Disagree }\end{array}$ & Agree & Strongly Agree \\
\hline $\begin{array}{l}\text { 2. Wearing the 7-MIL GLOVE } \\
\text { made it difficult to perform the text } \\
\text { entry task with the MOUSE. }\end{array}$ & Strongly Disagree & Disagree & $\begin{array}{c}\text { Neither Agree Nor } \\
\text { Disagree } \\
\square\end{array}$ & Agree & Strongly Agree \\
\hline $\begin{array}{l}\text { 3. Wearing the 14-MIL GLOVE } \\
\text { made it difficult to perform the text } \\
\text { entry task with the MOUSE. }\end{array}$ & Strongly Disagree & Disagree & $\begin{array}{l}\text { Neither Agree Nor } \\
\text { Disagree }\end{array}$ & Agree & Strongly Agree \\
\hline $\begin{array}{l}\text { 4. Wearing the 25-MIL GLOVE } \\
\text { made it difficult to perform the text } \\
\text { entry task with the MOUSE. }\end{array}$ & Strongly Disagree & Disagree & $\begin{array}{l}\text { Neither Agree Nor } \\
\text { Disagree }\end{array}$ & Agree & Strongly Agree \\
\hline $\begin{array}{l}\text { 5. When BAREHANDED, the text } \\
\text { entry task was difficult to perform } \\
\text { with the TOUCH PAD. }\end{array}$ & Strongly Disagree & Disagree & $\begin{array}{l}\text { Neither Agree Nor } \\
\text { Disagree }\end{array}$ & Agree & Strongly Agree \\
\hline $\begin{array}{l}\text { 6. Wearing the 7-MIL GLOVE } \\
\text { made it difficult to perform the text } \\
\text { entry task with the TOUCH PAD. }\end{array}$ & Strongly Disagree & Disagree & $\begin{array}{c}\text { Neither Agree Nor } \\
\text { Disagree } \\
\square\end{array}$ & Agree & Strongly Agree \\
\hline
\end{tabular}




\begin{tabular}{|c|c|c|c|c|c|}
\hline $\begin{array}{l}\text { 7. Wearing the 14-MIL GLOVE } \\
\text { made it difficult to perform the text } \\
\text { entry task with the TOUCH PAD. }\end{array}$ & Strongly Disagree & Disagree & $\begin{array}{l}\text { Neither Agree Nor } \\
\text { Disagree }\end{array}$ & Agree & Strongly Agree \\
\hline $\begin{array}{l}\text { 8. Wearing the 25-MIL GLOVE } \\
\text { made it difficult to perform the text } \\
\text { entry task with the TOUCH PAD. }\end{array}$ & Strongly Disagree & Disagree & $\begin{array}{c}\text { Neither Agree Nor } \\
\text { Disagree }\end{array}$ & Agree & Strongly Agree \\
\hline $\begin{array}{l}\text { 9. Wearing the MASK ALONE } \\
\text { made it difficult to perform the text } \\
\text { entry task with the MOUSE. }\end{array}$ & Strongly Disagree & Disagree & $\begin{array}{c}\text { Neither Agree Nor } \\
\text { Disagree }\end{array}$ & Agree & Strongly Agree \\
\hline $\begin{array}{l}\text { 10. Wearing the MASK ALONE } \\
\text { made it difficult to perform the text } \\
\text { entry task with the TOUCH PAD. }\end{array}$ & Strongly Disagree & Disagree & $\begin{array}{c}\text { Neither Agree Nor } \\
\text { Disagree }\end{array}$ & Agree & Strongly Agree \\
\hline $\begin{array}{l}\text { 11. Wearing the MASK and 7-MIL } \\
\text { GLOVES made it difficult to } \\
\text { perform the text entry task with the } \\
\text { MOUSE. }\end{array}$ & Strongly Disagree & Disagree & $\begin{array}{l}\text { Neither Agree Nor } \\
\text { Disagree } \\
\square\end{array}$ & Agree & Strongly Agree \\
\hline $\begin{array}{l}\text { 12. Wearing the MASK and 14-MIL } \\
\text { GLOVES made it difficult to } \\
\text { perform the text entry task with the } \\
\text { MOUSE. }\end{array}$ & Strongly Disagree & Disagree & $\begin{array}{l}\text { Neither Agree Nor } \\
\text { Disagree }\end{array}$ & Agree & Strongly Agree \\
\hline $\begin{array}{l}\text { 13. Wearing the MASK and 25-MIL } \\
\text { GLOVES made it difficult to } \\
\text { perform the text entry task with the } \\
\text { MOUSE. }\end{array}$ & Strongly Disagree & Disagree & $\begin{array}{l}\text { Neither Agree Nor } \\
\text { Disagree }\end{array}$ & Agree & Strongly Agree \\
\hline $\begin{array}{l}\text { 14. Wearing the MASK and 7-MIL } \\
\text { GLOVES made it difficult to } \\
\text { perform the text entry task with the } \\
\text { TOUCH PAD. }\end{array}$ & Strongly Disagree & Disagree & $\begin{array}{c}\text { Neither Agree Nor } \\
\text { Disagree }\end{array}$ & Agree & Strongly Agree \\
\hline
\end{tabular}




\begin{tabular}{|c|c|c|c|c|c|}
\hline $\begin{array}{l}\text { 15. Wearing the MASK and 14- } \\
\text { MIL GLOVES made it difficult to } \\
\text { perform the text entry task with the } \\
\text { TOUCH PAD. }\end{array}$ & Strongly Disagree & Disagree & $\begin{array}{c}\text { Neither Agree Nor } \\
\text { Disagree }\end{array}$ & Agree & Strongly Agree \\
\hline $\begin{array}{l}\text { 16. Wearing the MASK and 25- } \\
\text { MIL GLOVES made it difficult to } \\
\text { perform the text entry task with the } \\
\text { TOUCH PAD. }\end{array}$ & Strongly Disagree & Disagree & $\begin{array}{l}\text { Neither Agree Nor } \\
\text { Disagree }\end{array}$ & Agree & Strongly Agree \\
\hline $\begin{array}{l}\text { 17. I would feel confident using the } \\
\text { MOUSE during a military mission } \\
\text { to CREATE and SEND messages. }\end{array}$ & Strongly Disagree & Disagree & $\begin{array}{c}\text { Neither Agree Nor } \\
\text { Disagree }\end{array}$ & Agree & Strongly Agree \\
\hline $\begin{array}{l}\text { 18. I would feel confident using the } \\
\text { TOUCH PAD during a military } \\
\text { mission to CREATE and SEND } \\
\text { messages. }\end{array}$ & Strongly Disagree & Disagree & $\begin{array}{l}\text { Neither Agree Nor } \\
\text { Disagree }\end{array}$ & Agree & Strongly Agree \\
\hline $\begin{array}{l}\text { 19. I would feel confident using the } \\
\text { MOUSE during a military mission } \\
\text { to NAVIGATE through menus. }\end{array}$ & Strongly Disagree & Disagree & $\begin{array}{l}\text { Neither Agree Nor } \\
\text { Disagree }\end{array}$ & Agree & Strongly Agree \\
\hline $\begin{array}{l}\text { 20. I would feel confident using the } \\
\text { TOUCH PAD during a military } \\
\text { mission to NAVIGATE through } \\
\text { menus. }\end{array}$ & Strongly Disagree & Disagree & $\begin{array}{l}\text { Neither Agree Nor } \\
\text { Disagree }\end{array}$ & Agree & Strongly Agree \\
\hline $\begin{array}{l}\text { 21. Overall, I prefer to use the } \\
\text { for text entry (select an } \\
\text { input device). }\end{array}$ & Mouse & Touchpad & & & \\
\hline
\end{tabular}

Please provide any additional feedback in the space below or on the back of this paper. The feedback you provide will help us to design input devices that are easy to use, so completing this section is very important for our research. 
APPENDIX F. HEALTH AND DEMOGRAPHICS QUESTIONNAIRE 


\section{Health and Demographics Questionnaire}

Participant Number:

Date:

1. Are you currently on medical profile? (Circle One): Yes No

1a. If yes, please describe the problem(s) below:

2. Do you have any other current condition or are you currently taking any medications that may prevent you from performing the tasks described to you in the volunteer consent form? (Circle One): Yes No

3a. If yes, please describe the ailment(s) below:

3. What is your branch of service? (Circle One):

Air Force Army Marine Corps Navy Coast Guard

4. What is your age?

5. How long have you been in the service? years months

6. Please list below your MOS, ASI, NEC or AFS and briefly describe your job:

6a. How long have you been performing this MOS, ASI, NEC or AFS? years months

7. What is your gender? (Circle One): Male Female

8. Do you wear vision correction (glasses, contact lenses)? (Circle One): Yes No

8a. If yes, what type of vision correction do you wear most often? (Circle One):

Glasses

Contact Lenses

Other:

9. Do you typically wear vision corrective inserts with your current protective mask?

(Circle One): Yes No

10. Please rate your perceived level of experience with protective mask systems. (Circle One):

Very Experienced Experienced Slightly Experienced Not Experienced

11. If applicable, please circle all masks with which you have experience. (Circle all that apply): M40 series M42 MCU-2/P series M17 M45 Other:

12. If applicable, please circle the mask you currently use. (Circle One):
M40 series
M42
$\mathrm{MCU}-2 / \mathrm{P}$ series
M17
M45
Other: 
13. Have you ever had an adverse reaction, before, during or after wearing a mask?

(Circle One): Yes No

13a. If yes, please describe this reaction in detail:

14. Are you right or left handed? (Circle One): Left Right 


\title{
VITAE
}

\author{
ANDREA S. KRAUSMAN \\ 1121 Cold Spring Road \\ Baltimore, MD 21220 \\ ahynes@arl.army.mil
}

EDUCATION:

08/97 - Present Virginia Polytechnic Institute and State University

Blacksburg, VA

MS, INDUSTRIAL AND SYSTEMS ENGINEERING

Degree: Expected December 2004

08/85 - 05/90 Alfred University, Alfred, New York

B.A. EXPERIMENTAL PSYCHOLOGY

Degree: May 1990

PROFESSIONAL EXPERIENCE:

12/90 - Present $\quad$ U.S. Army Research Laboratory RESEARCH PSYCHOLOGIST

Responsible for designing, coordinating, and conducting human factors research focused on optimizing soldier systems. Also responsible for performing human factors engineering assessments and system evaluations to ensure effective system design and integration.

HONORS \& AWARDS:

Alpha Pi Mu Industrial Engineering Honor Society, Virginia Tech, 2001.

Performance Awards for Exceptional Service, ARL (1992-1997)

MEMBERSHIPS

Student Member, Human Factors and Ergonomics Society (HFES), 2000-2002

Member, HFES Student Chapter, Virginia Tech, 2000-2002

\section{PUBLICATIONS}

Krausman, A., Boynton, A., Harper, W., Ortega, S., and Wilson, R. Human Factors Evaluation of Land Warrior, Version 1.0; ARL-TR-3205; U.S. Army Research Laboratory: Aberdeen Proving Ground, MD , 2004.

Krausman, A., Crowell, H.P., and Wilson, R. The effects of physical exertion on cognitive performance, ARL-TR2844; U.S. Army Research Laboratory: Aberdeen Proving Ground, MD, 2002.

Crowell, H.P., Krausman, A., Harper, W., Faugh, J., Sharp, M., Mello, R.P., Smith, T., and Patton, J. Cognitive and physiological performance of soldiers while they carry loads over various terrains, ARL-TR-1779; U.S. Army

Research Laboratory: Aberdeen Proving Ground, MD, 1997.

Krausman, A., Savick, D., Leiter, K., Faughn, J., and Knapik, J. Measurement of energy expenditure on the Uniport Mobility Platform, ARL-TR-1263, U.S. Army Research Laboratory: Aberdeen Proving Ground, MD, 1996. 
Savick, D., Krausman, A., Leiter, K., and Faughn, J. Validation of Speed and Stride on the Uniport Mobility Platform, ARL-TN-75, U.S. Army Research Laboratory: Aberdeen Proving Ground, MD, 1996. 